\title{
Experimental and numerical evaluation of the effectiveness of a stiff wave barrier in the soil
}

\author{
P. Coulier ${ }^{\mathrm{a}, *}$ V. Cuéllar ${ }^{\mathrm{b}}$, G. Degrande ${ }^{\mathrm{a}}$, G. Lombaert $^{\mathrm{a}}$ \\ ${ }^{a} K U$ Leuven, Department of Civil Engineering, Kasteelpark Arenberg 40, 3001 Leuven, Belgium \\ ${ }^{b}$ CEDEX, Laboratoria de Geotecnia, Alfonso XII 3, 28014 Madrid, Spain
}

\begin{abstract}
This paper discusses the design, the installation, and the experimental and numerical evaluation of the effectiveness of a stiff wave barrier in the soil as a mitigation measure for railway induced vibrations. A full scale in situ experiment has been conducted at a site in El Realengo (Spain), where a barrier consisting of overlapping jet grout columns has been installed along a railway track. This barrier is stiff compared to the soil and has a depth of $7.5 \mathrm{~m}$, a width of $1 \mathrm{~m}$, and a length of $55 \mathrm{~m}$. Geophysical tests have been performed prior to the installation of the barrier for the determination of the dynamic soil characteristics. Extensive measurements have been carried out before and after installation of the barrier, including free field vibrations during train passages, transfer functions between the track and the free field, and the track receptance. Measurements have also been performed at a reference section adjacent to the test section in order to verify the effect of changing train, track, and soil conditions over time. The in situ measurements show that the barrier is very effective: during train passages, a reduction of vibration levels by $5 \mathrm{~dB}$ is already obtained from $8 \mathrm{~Hz}$ upwards, while a peak reduction of about $12 \mathrm{~dB}$ is observed near $30 \mathrm{~Hz}$ immediately behind the barrier. The performance decreases further away from the jet grouting wall, but remains significant. The experimental results are also compared to numerical simulations based on a coupled finite element boundary element methodology. A reasonable agreement between experiments and predictions is found, largely confirming the initially predicted reduction. This in situ test hence serves as a 'proof of concept', demonstrating that stiff wave barriers are capable of significantly reducing vibration levels, provided that they are properly designed.
\end{abstract}

Keywords: Railway induced vibrations, stiff wave barrier, in situ experiment, vibration mitigation.

\section{Introduction}

Railway induced vibrations can lead to annoyance for residents of nearby buildings. During the past decades, a lot of research has been performed to develop efficient and cost-effective vibration countermeasures

\footnotetext{
*Corresponding author. Phone: + 32163223 78. Fax: + 3216321988.

Email address: pieter.coulier@bwk.kuleuven.be (P. Coulier)

Postprint published in Soil Dynamics and Earthquake Engineering
} 
for reducing excessive levels of building vibration $[1,2,3]$. Measures can either be taken at the source (railway track) $[4,5,6]$, on the propagation path between source and receiver $[7,8,9]$, or at the receiver (building) $[10,11]$. An advantage of interventions on the propagation path is that no modifications to the track are required, while multiple buildings can be protected simultaneously from vibration. Furthermore, this type of measures can relatively easily be implemented along an existing track.

A basic type of a mitigation measure on the propagation path is an open trench in the soil. The latter aims at reflecting the impinging waves and is expected to be effective if its depth is comparable to the penetration depth of the Rayleigh waves in the soil. The effectiveness of open trenches has been investigated numerically by many authors as Woods [12], Segol et al. [13], Beskos et al. [14], Klein et al. [15], and Connolly et al. [16]. For stability reasons, the construction of an open trench in the soil is limited to shallow depths. Furthermore, an open trench can easily get inundated due to surface water run-off or groundwater infiltration, posing concerns on effectiveness, durability, and safety. The use of either soft (polystyrene [9], rubber chips [17]) or stiff (concrete, grout) in-fill materials (compared to the original soil) allows reaching larger depths and results in a more sustainable solution. Various numerical approaches have been explored for predicting the effectiveness of open and in-filled trenches, such as the finite element (FE) [18], the boundary element (BE) [19], or coupled FE-BE methods [9]. Other examples of vibration mitigation measures on the propagation path include buried wall barriers [20], wave impeding blocks [21], rows of piles [22, 23], and heavy masses placed along a railway track for scattering the incident surface waves [24, 25].

Although numerical simulations are indispensable for understanding and designing efficient wave barriers, there remains a strong need to validate the outcome of these simulations by means of in situ tests. Early experiments with trenches have been reported by Woods [12], while results from more recent field measurements involving open and filled trenches have been presented by Al-Hussaini et al. [26] and Çelebi et al. [27]. The use of a soft geofoam in-fill material has been assessed experimentally by Alzawi and El Naggar [18]; François et al. [9] describe the design and efficiency of a composite vibration isolation screen near a tramway in Brussels. In most of the aforementioned experiments, the length of the vibration isolation screens was limited to a few meters and only artificial excitation sources such as impact hammers or harmonic shakers were employed for assessing the isolation performance. Examples of longer screens (tens of meters) can be found in Sweden and Germany, where gas-filled cushions have been installed and tested [28, 29]. Apart from in situ experiments, complementary small scale laboratory tests are also valuable. Haupt [30] presents model tests of various types of barriers, while Murillo et al. [31] have investigated the efficiency of expanded polystyrene (EPS) barriers by means of centrifuge tests. A small scale experimental study of a stiff wave barrier in gelatine has been reported in [32].

This paper presents a full scale in situ experiment that has been specifically designed for assessing the performance of stiff wave barriers in the soil. The circumstances in which such barriers are expected to be effective have been analysed in detail in [33] by means of state-of-the-art numerical simulations, highlighting 
how their performance critically depends on site specific characteristics such as dynamic soil properties. Furthermore, the physical mechanism that results in a reduction of vibration levels for stiff barriers has been identified and was found to fundamentally differ from that of open trenches or soft barriers. Based on these findings, a field test has been designed and carried out in Spain within the frame of the EU FP7 project RIVAS (Railway Induced Vibration Abatement Solutions) [34], which forms the topic of the present paper.

The outline of this paper is as follows. Section 2 introduces the test site in Spain and addresses the determination of the dynamic soil characteristics. The design and construction of the stiff wave barrier are also discussed, while the main physical principles affecting the performance of this type of barrier are briefly reviewed. The results of extensive measurement campaigns are subsequently presented in section 3 , including the free field response during train passages before and after installation of the barrier, the transfer functions between the track and the free field, and track receptance tests. The experimental results are finally compared to coupled FE-BE simulations in section 4. Conclusions are drawn in section 5.

\section{Experimental setup}

\subsection{Description of the test site}

A suitable site for testing a stiff wave barrier was identified in El Realengo (south-east of Spain) along the conventional railway line between Murcia and Alicante. The track at this site is a classical ballasted track with bi-block reinforced concrete sleepers supporting RN 45 rails with Spanish wide gauge $(1.668 \mathrm{~m})$. It is supported by a ballast layer and an embankment, each $0.50 \mathrm{~m}$ high. Geotechnical studies, performed in preparation of the construction of a new high speed railway line next to the conventional line, indicated the presence of soft silty clay soil layers with a thickness of approximately $10 \mathrm{~m}$ on top of stiffer alluvial soil. These are particular circumstances where a stiff wave barrier is expected to be very effective [33]. At the site, a test section as well as a reference section were chosen, as indicated on figure 1 . The center-to-center distance between these sections equals $100 \mathrm{~m}$. The jet grouting wall is implemented along the test section; the aim of the reference section is to verify the effect of changing track, train, and soil conditions over time. This is important when evaluating the mitigation performance of the wave barrier, as will be discussed in detail in section 3 .

\subsection{Determination of the dynamic soil characteristics}

As numerical simulations indicate that the vibration mitigation efficiency of a stiff wave barrier strongly depends on the dynamic soil characteristics [33], several geotechnical and geophysical tests were carried out for an accurate determination of these properties. Two down-hole tests were performed using a seismic piezocone pushed vertically in the soil and equipped with a triaxial accelerometer mounted on a probe 


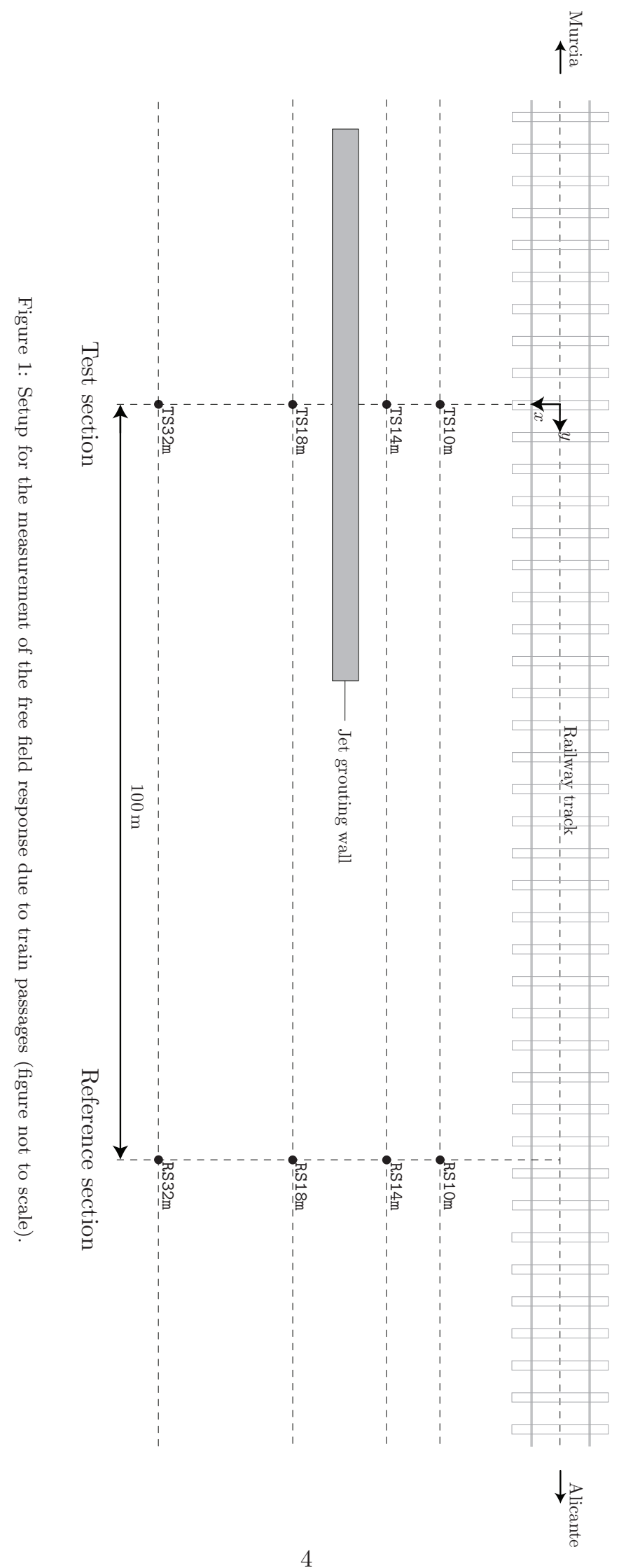


adapter. A horizontal impulse was applied at the soil's surface by means of a sledge-hammer in order to generate shear waves and the wave arrival times were recorded at different depths. At each depth, the shear wave velocity was calculated from the travel time of the waves. The two down-hole tests were carried out up to a depth of $14.5 \mathrm{~m}$ and $11.5 \mathrm{~m}$, respectively; a $1 \mathrm{~m}$ depth interval between measurements was adopted. The down-hole tests do not provide an accurate estimation of the shear wave velocity in shallow soil layers, however, and have therefore been complemented with four Spectral Analysis of Surface Waves (SASW) tests. An impact deflectometer was used for applying a vertical impact at the soil's surface, while the vertical response was measured by means of pairs of accelerometers and geophones. The solution of an inverse problem allowed for the determination of a shear wave velocity profile. Finally, seismic refraction tests were carried out along four measurement lines at the soil's surface. Hammer impacts on a steel plate were used as excitation, while 24 geophones were employed for measuring the resulting vertical velocity along straight lines with a length of $46 \mathrm{~m}$, using a sampling frequency of $5 \mathrm{kHz}$. The intercept time method [35] was used in combination with a linear least squares method and a delay time analysis to invert the first time arrivals of the dilatational waves obtained at each measurement line. Apart from SASW tests, seismic piezocone down-hole tests, and seismic refraction tests, transfer functions in the free field and from the track to the free field were also measured at both the test and the reference section. These free field transfer functions have been used for the determination of the material damping ratios $\beta_{\mathrm{s}}$ and $\beta_{\mathrm{p}}$ in deviatoric and volumetric deformation. This was done by fitting the predicted free field transfer functions to the measurements, where the Arias intensity [36] was used to characterize the intensity of the ground motion. This intensity is a measure of the total energy at a certain point within a certain time period.

Based on the results of the tests described above, a simplified horizontally layered soil model was identified, as summarized in table 1. The soil densities given in the table are those determined from undisturbed samples retrieved from boreholes drilled in preparation of the construction of the new high speed railway line. The identified soil profile, consisting of a soft layer with a thickness of approximately $10 \mathrm{~m}$ (layers 2 and 3) that overlies hard alluvial soil, is in line with the expectations for this site. The soil is saturated at depths below $1.50 \mathrm{~m}$ due to the presence of the ground water table. This leads to a high dilatational wave velocity $C_{\mathrm{p}}$ for layers 3,4 , and 5 .

The dynamic soil characteristics summarized in table 1 have subsequently been used to calculate free field transfer functions. Figure 2 shows the transfer functions between a vertical point source and the vertical velocity at $8 \mathrm{~m}$ and $16 \mathrm{~m}$ from the source. With increasing distance from the source, the transfer functions show a stronger decrease at higher frequencies due to material damping in the soil. The predictions are compared to the mean value and the $95 \%$ confidence interval of the measured transfer functions at the test and reference section. The latter have been determined using the $H_{1}$-estimator, which is based on the average cross and auto power spectral densities [37]. A good agreement is found between the predictions and the experimental results, in particular in the frequency range up to $50 \mathrm{~Hz}$. This demonstrates that the dynamic 


\begin{tabular}{ccccccc}
\hline Layer & $\begin{array}{c}h \\
{[\mathrm{~m}]}\end{array}$ & $\begin{array}{c}C_{\mathrm{s}} \\
{[\mathrm{m} / \mathrm{s}]}\end{array}$ & $\begin{array}{c}C_{\mathrm{p}} \\
{[\mathrm{m} / \mathrm{s}]}\end{array}$ & $\begin{array}{c}\beta_{\mathrm{s}} \\
{[-]}\end{array}$ & $\begin{array}{c}\beta_{\mathrm{p}} \\
{[-]}\end{array}$ & $\begin{array}{c}\rho \\
{\left[\mathrm{kg} / \mathrm{m}^{3}\right]}\end{array}$ \\
\hline 1 & 0.30 & 270 & 560 & 0.123 & 0.123 & 1800 \\
2 & 1.20 & 150 & 470 & 0.112 & 0.112 & 1750 \\
3 & 8.50 & 150 & 1560 & 0.014 & 0.014 & 1750 \\
4 & 10.00 & 475 & 1560 & 0.010 & 0.010 & 1900 \\
5 & $\infty$ & 550 & 2030 & 0.010 & 0.010 & 1900 \\
\hline
\end{tabular}

Table 1: Dynamic soil characteristics at the site in El Realengo.

soil properties have been identified with sufficient accuracy for making reliable numerical predictions. The signal-to-noise ratio decreases at higher frequencies which leads to a large confidence interval, however, making it more difficult to assess the accuracy of the predictions. Furthermore, figure 2 shows a significant difference between the transfer functions measured at the test and reference section, hence indicating a spatial variability of the dynamic soil characteristics.
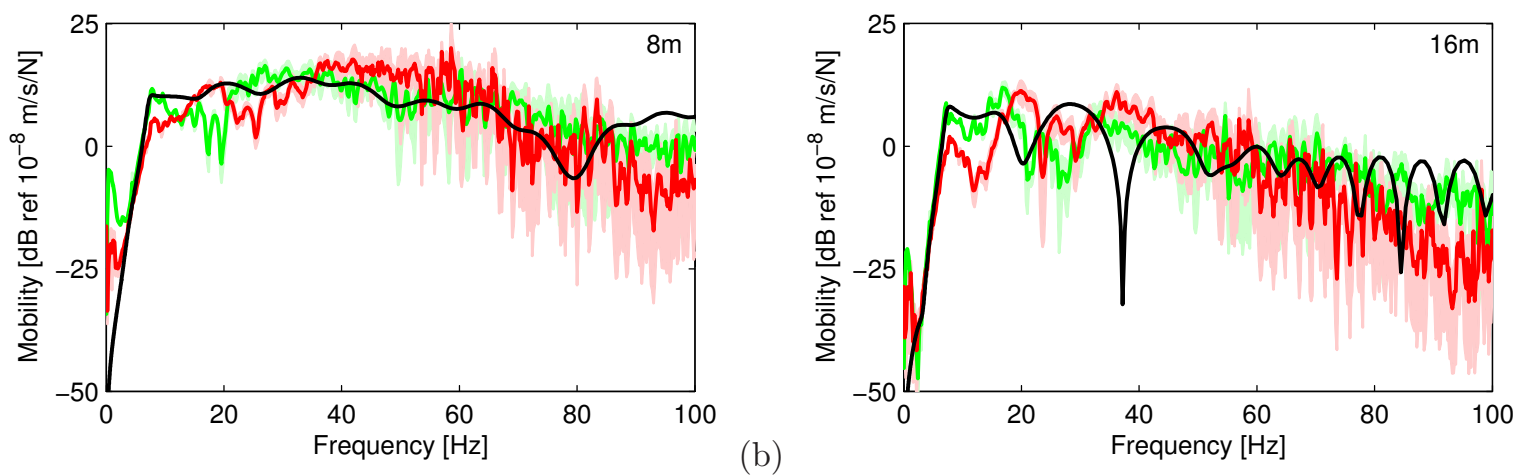

(a)

Figure 2: Predicted free field transfer functions (black line) compared to the experimental results at the test (red line) and reference (green line) section at (a) $8 \mathrm{~m}$ and (b) $16 \mathrm{~m}$ from the impact point. The $95 \%$ confidence interval of the measurements is indicated as a shaded area.

It is also instructive to investigate the wave propagation in the idealized layered halfspace. Figure 3 shows the computed frequency-wavenumber spectrum of the vertical free field velocity $i \omega \tilde{u}_{z}\left(C_{r}, \omega\right)$ due to vertical harmonic excitation at the surface of the layered halfspace, presented as a function of the phase velocity $C_{r}=\omega / k_{r}$ instead of the wavenumber $k_{r}$. Peaks in the spectrum of $i \omega \tilde{u}_{z}\left(C_{r}, \omega\right)$ correspond to surface waves of the layered halfspace; multiple modes with associated cut-on frequencies exist in the frequency range considered. The spectrum is dominated by the fundamental Rayleigh wave, of which the dispersion curve is superimposed on figure 3. The corresponding Rayleigh wave velocity varies strongly at low frequencies but remains almost constant (between $148 \mathrm{~m} / \mathrm{s}$ and $162 \mathrm{~m} / \mathrm{s}$ ) from $20 \mathrm{~Hz}$ to $100 \mathrm{~Hz}$. As will be clarified in 
the next subsection, the relation between the Rayleigh wave velocity in the soil and the velocity of bending waves in the stiff wave barrier determines the vibration reduction effectiveness of the barrier.

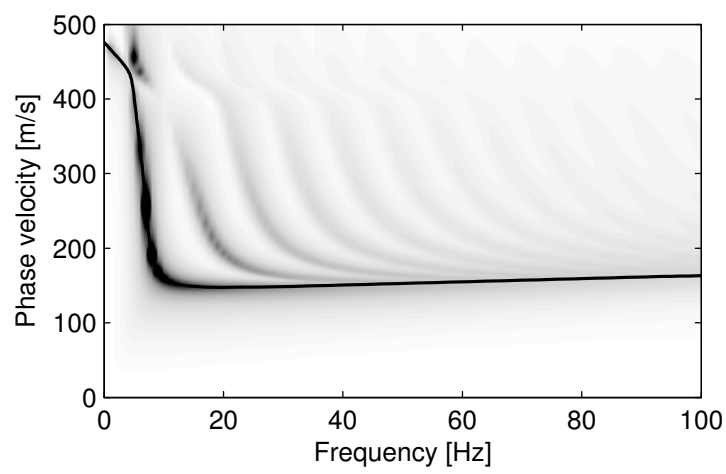

Figure 3: Predicted frequency-wavenumber spectrum of the vertical free field velocity $i \omega \tilde{u}_{z}\left(C_{r}, \omega\right)$ due to vertical harmonic excitation at the surface of the layered halfspace. Superimposed is the dispersion curve of the fundamental Rayleigh wave.

\subsection{Design of the stiff wave barrier}

Numerical simulations have revealed that a stiff wave barrier in the soil can be a very effective vibration countermeasure, with a reduction determined by the interaction between Rayleigh waves in the soil and bending waves in the barrier $[33,38]$. The mechanism that leads to a reduction of free field vibrations is concisely summarized in the following paragraphs; the reader is referred to $[33,38]$ for a detailed discussion.

Figure 4a shows the real part of the vertical displacement $u_{z}(\mathbf{x}, f)$ in the soil due to a unit harmonic point load at $5 \mathrm{~Hz}$ and $15 \mathrm{~Hz}$ at the surface of the halfspace, if no barrier is present. The railway track is disregarded in order to facilitate physical interpretation. The propagation of Rayleigh waves can clearly be observed. The wavefield in the case of an infinitely long stiff barrier (with a depth of $7.5 \mathrm{~m}$, a width of $1 \mathrm{~m}$, and dynamic characteristics as listed in table 2) embedded in the soil is shown in figure 4b. The barrier's vibration reduction effectiveness is quantified through the vertical insertion loss $\mathrm{IL}_{z}(\mathbf{x}, f)=20 \log _{10}\left(\left|u_{z}^{\mathrm{ref}}(\mathbf{x}, f)\right| /\left|u_{z}(\mathbf{x}, f)\right|\right)$ in figure 4c, where positive values of the insertion loss indicate a reduction of the vertical free field vibrations. Figure 4c indicates that the barrier is unable to impede the propagation of Rayleigh waves at $5 \mathrm{~Hz}$, while a significant reduction of vibration levels is achieved at $15 \mathrm{~Hz}$, but only in a limited area behind the barrier.

The observations in figure 4 can be explained by considering a decomposition of the wavefield into plane waves, satisfying the Rayleigh wave dispersion relation $1 / \lambda_{x}^{2}+1 / \lambda_{y}^{2}=1 / \lambda_{\mathrm{R}}^{2}(f)$ [39]. For propagating plane waves, the trace wavelength $\lambda_{y}$ observed by the barrier is situated between $\lambda_{y}=\infty$ (for plane waves impinging perpendicularly on the barrier) and $\lambda_{y}=\lambda_{\mathrm{R}}(f)=C_{\mathrm{R}}(f) / f$ (for plane waves travelling along the barrier), where $C_{\mathrm{R}}(f)$ is the frequency dependent velocity of the fundamental Rayleigh wave in the soil. Figure 5a compares $C_{\mathrm{R}}(f)$ to the velocity of a free bending wave in the stiff wave barrier $C_{\mathrm{b}}(f)$. 

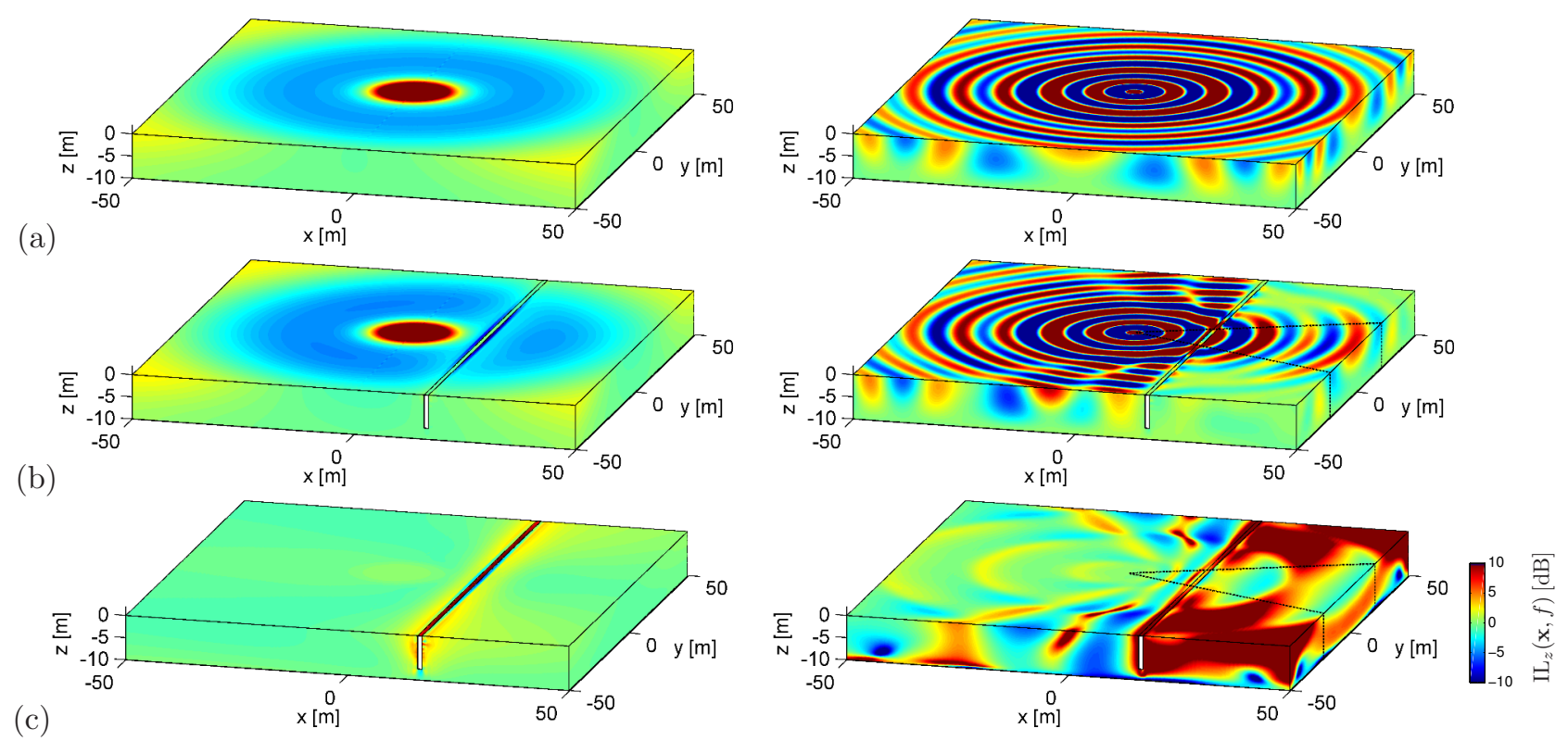

Figure 4: Real part of the vertical displacement $u_{z}(\mathbf{x}, f)$ due to harmonic excitation at $5 \mathrm{~Hz}$ (left hand side) and $15 \mathrm{~Hz}$ (right hand side) (a) without and (b) with a stiff wave barrier. The corresponding insertion loss $\operatorname{IL}_{z}(\mathbf{x}, f)$ is shown in (c). The dotted lines in (b) and (c) delimit $2 \theta_{\mathrm{c}}(f)$.

The latter is obtained using Timoshenko beam theory and assuming bending with respect to the barrier's horizontal axis. At low frequencies (i.e. $5 \mathrm{~Hz}$ in figure 4), the Rayleigh wave velocity $C_{\mathrm{R}}(f)$ is larger than the bending wave velocity $C_{\mathrm{b}}(f)$ and all plane waves in the soil have a trace wavelength $\lambda_{y}$ larger than the free bending wavelength $\lambda_{\mathrm{b}}(f)=C_{\mathrm{b}}(f) / f$ of the barrier $\left(\lambda_{\mathrm{b}}(f)<\lambda_{\mathrm{R}}(f) \leq \lambda_{y} \leq \infty\right)$. These waves propagate unhindered through the barrier, as observed in figure 4 . If the velocity $C_{\mathrm{R}}(f)$ matches the velocity $C_{\mathrm{b}}(f)$, a critical frequency $f_{\mathrm{c}}$ is attained. From this critical frequency $f_{\mathrm{c}}=6.5 \mathrm{~Hz}$ upwards, the wavefield contains plane waves in the soil with a trace wavelength $\lambda_{y}$ that is smaller than the free bending wavelength $\lambda_{\mathrm{b}}(f)$. The transmission of these plane waves is impeded by the stiff barrier, as the latter's bending stiffness varies proportionally to $\left(\lambda_{\mathrm{b}} / \lambda_{y}\right)^{4}$ at a given frequency. Waves with a trace wavelength $\lambda_{y}$ larger than $\lambda_{\mathrm{b}}(f)$ remain unaffected by the presence of the barrier, however. As a result, a reduction of vibration levels is only achieved in an area delimited by a critical angle $\theta_{\mathrm{c}}(f)=\sin ^{-1}\left(C_{\mathrm{R}}(f) / C_{\mathrm{b}}(f)\right)$, which can clearly be distinguished at $15 \mathrm{~Hz}$ on figure 4. The variation of the critical angle with frequency is shown in figure 5b, ranging from $\theta_{\mathrm{c}}\left(f_{\mathrm{c}}\right)=90^{\circ}$ at the critical frequency to $\theta_{\mathrm{c}}(f)=\sin ^{-1}\left(C_{\mathrm{R}}(f) /\left(C_{\mathrm{s}} \sqrt{\kappa}\right)\right)$ at limiting high frequencies, where $C_{\mathrm{s}}$ and $\kappa$ are the shear wave velocity and shear coefficient of the barrier, respectively [33].

It follows from the discussion above that the effectiveness of a stiff wave barrier critically depends on how $C_{\mathrm{R}}(f)$ relates to $C_{\mathrm{b}}(f)$. An increase of the latter can either be achieved by an increase of the barrier's Young's modulus or its bending moment of inertia. In addition to the wave impeding effect, a further 

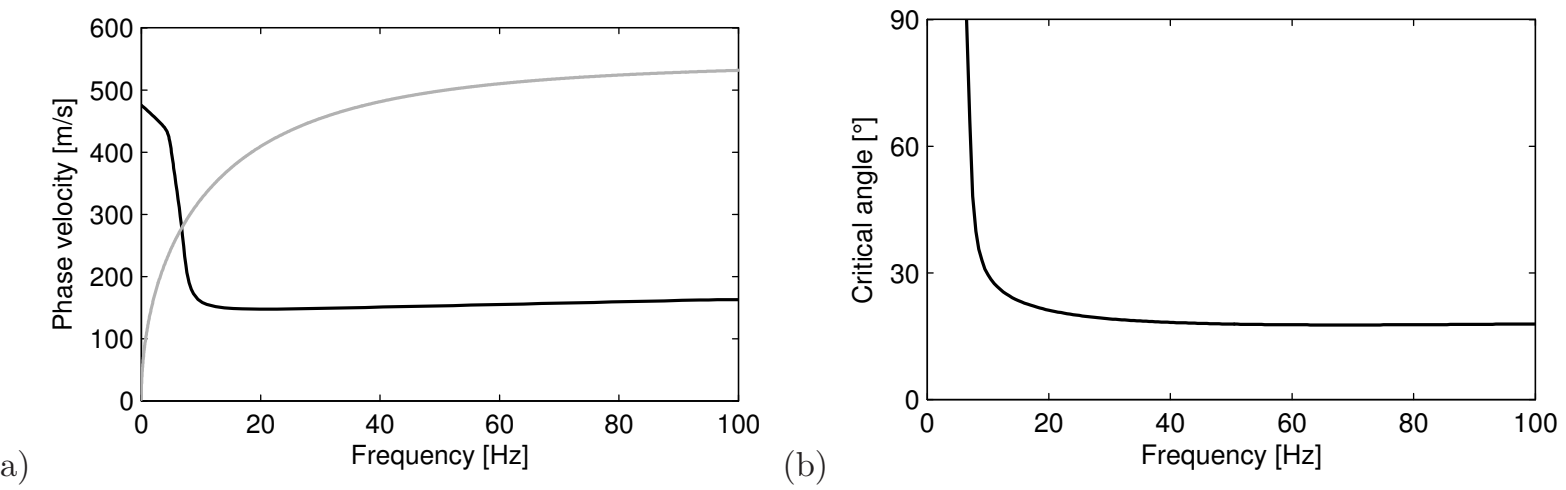

Figure 5: (a) Phase velocity $C_{\mathrm{R}}(f)$ of the fundamental Rayleigh wave in the soil (black line) compared to the phase velocity $C_{\mathrm{b}}(f)$ of bending waves in the stiff barrier (grey line). (b) The critical angle $\theta_{\mathrm{c}}(f)=\sin ^{-1}\left(C_{\mathrm{R}}(f) / C_{\mathrm{b}}(f)\right)$ as a function of frequency.

reduction of vibration levels is caused by reflections of the impinging Rayleigh waves (cfr. the behaviour of an open trench), which is only achieved if the depth of the barrier is greater than about 0.60 times the Rayleigh wavelength in the soil. This phenomenon is independent of the trace wavelength $\lambda_{y}$, however, explaining why a reduction is also observed in the central area behind the barrier at $15 \mathrm{~Hz}$ in figure 4c.

If the passage of a train is considered (rather than transfer functions as in figure 4), several dynamic axle loads contribute to the ground vibration at a certain receiver point of interest in the free field. Due to the existence of the critical angle $\theta_{c}(f)$, the contribution of the axle loads moving towards or away from the receiver will be reduced more effectively than the contribution of the axle loads located near the receiver. The largest reduction is therefore expected at locations close to the track (as the contribution of a larger number of axle loads is mitigated) and, at a particular location, at high frequencies (due to the decreasing critical angle).

The principles outlined above have been employed together with additional coupled FE-BE computations for designing a barrier in El Realengo that could be effective from approximately $10 \mathrm{~Hz}$ upwards. Following parameters have been used for the barrier in the preliminary design [40]: a shear wave velocity varying between $C_{\mathrm{s}}=400 \mathrm{~m} / \mathrm{s}$ and $C_{\mathrm{s}}=650 \mathrm{~m} / \mathrm{s}$, a Poisson's coefficient $\nu=0.25$, a density $\rho=2200 \mathrm{~kg} / \mathrm{m}^{3}$, a width ranging from $0.5 \mathrm{~m}$ to $1.5 \mathrm{~m}$, and a depth between $5 \mathrm{~m}$ and $7.5 \mathrm{~m}$. Using these parameters, along with the soil characteristics described in table 1, a barrier with a depth of $7.5 \mathrm{~m}$, a width of $1 \mathrm{~m}$, and a length of $55 \mathrm{~m}$ was proposed.

\subsection{Installation of the jet grouting wall}

Several construction techniques are available for creating a stiff wave barrier in the soil, such as deep vibro compaction, the installation of gravel or cement columns, hydraulic fracture injection with stable cementbentonite mixtures, and vacuum consolidation. Jet grouting was selected as an appropriate technique for the 
site in El Realengo due to its versatility and possibility to strengthen a wide range of weak natural soils. Jet grouting is a bottom-up procedure, where grout is injected under high pressure at the design depth in order to initiate the erosion of the soil. A uniform rotation and lifting of the nozzle hence allows for the creation of in situ cemented column formations, while the spoil material is expelled at the top of the borehole. 60 overlapping grout columns with a diameter of $1.5 \mathrm{~m}$ and a centre-to-centre distance of $0.9 \mathrm{~m}$ were installed to create a stiff wave barrier with an overall length of $55 \mathrm{~m}$ and a width of $1 \mathrm{~m}$. This was achieved using a monofluid consisting of $90 \mathrm{~kg}$ of cement per $100 \mathrm{l}$ of water injected under a pressure of $40,000 \mathrm{kN} / \mathrm{m}^{2}$, while maintaining a flow rate of $310-320 \mathrm{l} / \mathrm{min}$, a nozzle lift speed of $200 \mathrm{~mm} / \mathrm{min}$, and a nozzle rotation speed of $20 \mathrm{rpm}$ during the whole injection procedure. Figure 6a shows the equipment that has been employed for creating the jet grout columns, while the surface of the resulting wave barrier is shown in figure $6 \mathrm{~b}$. For safety reasons and due to the presence of a water duct, the barrier could only be constructed at a distance of $16.2 \mathrm{~m}$ from the center of the railway track. More details related to the installation of the jet grouting wall (e.g. risk assessment, life cycle costs, ...) can be found in [41, 42].

(a)

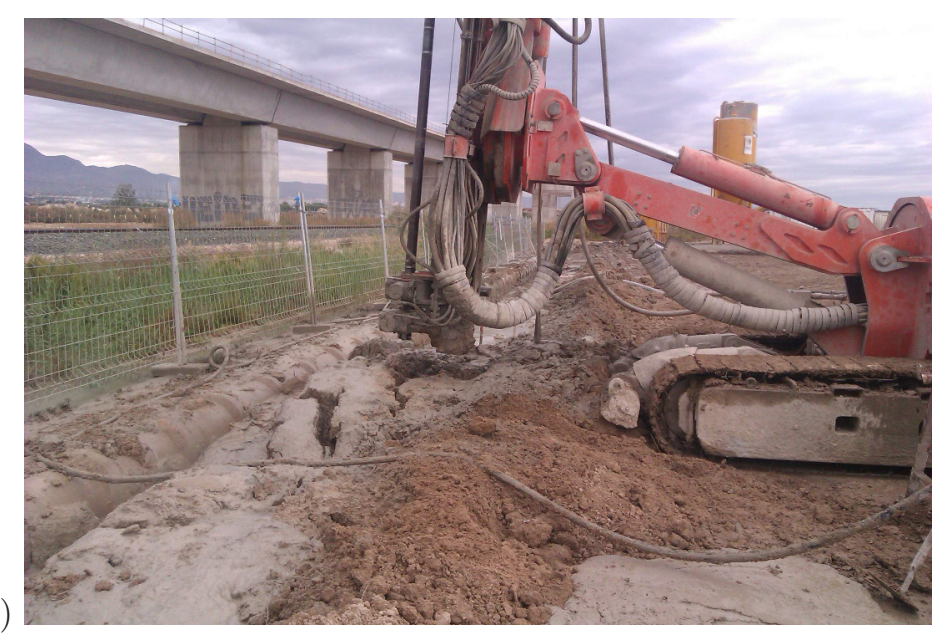

(b)

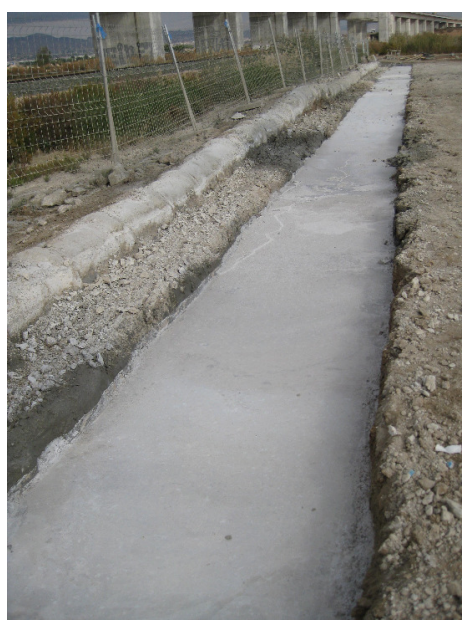

Figure 6: (a) Construction of the jet grout columns and (b) the stiff wave barrier upon completion at the site of El Realengo.

Five test columns were realized prior to the construction of the jet grouting wall. Furthermore, multiple test samples have been taken during the installation of the individual columns to verify their strength and stiffness. Laboratory tests (unconfined compression tests, non-dispersive $\mathrm{P}-\mathrm{S}$ sonic tests, dispersive bender element tests) have been performed on these samples; the best estimate of the dynamic characteristics (two months after construction) is given in table 2 . The shear wave velocity $C_{\mathrm{s}}$ is situated between the lower and upper bound employed in the preliminary design. The lower part of the barrier is saturated, resulting in a higher dilatational wave velocity $C_{\mathrm{p}}$ and density $\rho$ below a depth of $1.50 \mathrm{~m}$. 


\begin{tabular}{ccccccc}
\hline Layer & $h$ & $C_{\mathrm{s}}$ & $C_{\mathrm{p}}$ & $\beta_{\mathrm{s}}$ & $\beta_{\mathrm{p}}$ & $\begin{array}{c}\rho \\
{[\mathrm{m}]}\end{array}$ \\
{$[\mathrm{m} / \mathrm{s}]$} & {$[\mathrm{m} / \mathrm{s}]$} & {$[-]$} & {$[-]$} & {$\left[\mathrm{kg} / \mathrm{m}^{3}\right]$} \\
\hline 1 & 1.50 & 600 & 1150 & $0.03^{\star}$ & $0.03^{\star}$ & 1400 \\
2 & 6.00 & 600 & 1650 & $0.03^{\star}$ & $0.03^{\star}$ & 1750 \\
\hline
\end{tabular}

Table 2: Dynamic characteristics of the jet grouting wall. Estimated values are indicated by a star.

\section{Experimental evaluation of the vibration mitigation performance}

Extensive measurement campaigns have been carried out before and after installation of the stiff wave barrier in El Realengo in order to evaluate its performance. This includes the measurement of the free field response due to train passages, transfer functions between the track and the free field, and track receptance tests. The experimental results are discussed in the following. The installation of the barrier took place in November 2013. Reference train passages and transfer functions (i.e. before construction of the barrier) were measured in October 2013 and August 2012, respectively, while similar measurements were performed in December 2013 after the barrier's construction.

\subsection{The free field response due to train passages}

Passages of three different train types were recorded at the El Realengo site, before (October 2013) and after (December 2013) construction of the jet grouting wall: S592 commuter trains, S599 medium distance trains, and long distance Talgo VI trains. These are train passages on the classical ballasted track; the new high speed railway line was not in operation yet at the time of the experimental campaigns. In this paper, only results obtained during the passage of S592 commuter trains are discussed, as similar trends are found for the other train types. The S592 commuter train is a short train consisting of three carriages. Each carriage has two bogies, while each bogie is supported by two axles. The train has a total length of $65 \mathrm{~m}$ between the first and last axle. Each axle has an estimated unsprung mass of $2000 \mathrm{~kg}$. As only a single track is present at the site, both train passages from Murcia to Alicante and vice versa are recorded. The train velocities are estimated from strain measurements on the rails at the reference and test section. Ten and eleven passages of S592 trains have been recorded in October and December 2013, respectively, with a train speed varying between $112 \mathrm{~km} / \mathrm{h}$ and $122 \mathrm{~km} / \mathrm{h}$ (with an average speed of $117 \mathrm{~km} / \mathrm{h}$ ). The rail response was measured using piezoelectric accelerometers (with a sensitivity of $0.1 \mathrm{~V} / \mathrm{g}$ ) anchored to the rail by cyanoacrylate adhesives. Free field vertical vibration velocities were measured by means of geophones along a line perpendicular to the track, at $10 \mathrm{~m}, 14 \mathrm{~m}, 18 \mathrm{~m}$, and $32 \mathrm{~m}$ from the outer rail, both at the reference and test section (and thus at $10.834 \mathrm{~m}, 14.834 \mathrm{~m}, 18.834 \mathrm{~m}$, and $32.834 \mathrm{~m}$ from the center of the track). These locations are referred to as RSxx and TSxx in the following, respectively, where the label $\mathrm{xx}$ represents the distance from the outer rail. The receiver locations at $18 \mathrm{~m}$ and $32 \mathrm{~m}$ at the test section are 
situated behind the jet grouting wall, as indicated on figure 1 . The $1 \mathrm{~Hz}$ geophones have a sensitivity of $170 \mathrm{~V} / \mathrm{m} / \mathrm{s}$; a sampling frequency of $10 \mathrm{kHz}$ was used. Only vertical vibration velocities were recorded in this test, although vibrations in the transversal and longitudinal direction might also be of interest in practical situations [43].

Figure 7 shows the time history and frequency content of the vertical rail velocity at the test and reference section during the passage of a 5592 commuter train at a speed of $117 \mathrm{~km} / \mathrm{h}$ in December 2013, i.e. after construction of the jet grouting wall. This particular train runs from Murcia to Alicante, implying that it first passes the test section and subsequently the reference section, as can be observed in figure 7 . The passage of each individual axle is clearly apparent in the time history, while the quasi-discrete spectrum is mainly situated below $20 \mathrm{~Hz}$. The response at the reference and test section are very similar, indicating that the track conditions at the reference and test section are alike, but also that the presence of the jet grouting wall has little effect on the response of the rail (as expected from numerical simulations [33]).
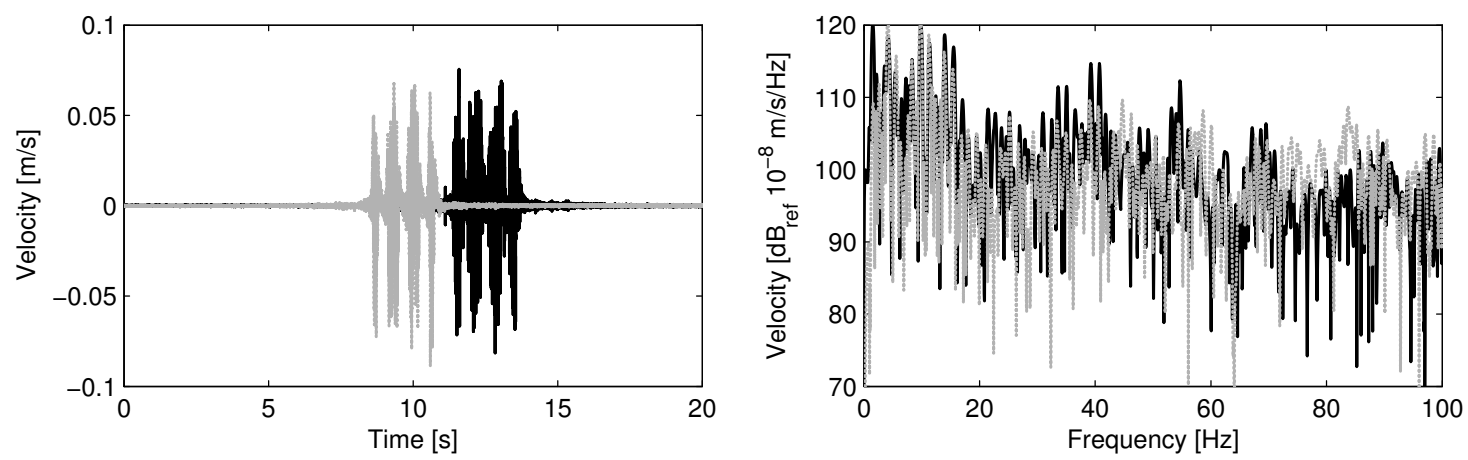

Figure 7: Time history (left) and frequency content (right) of the measured vertical rail velocity during the passage of a S592 commuter train at a speed of $117 \mathrm{~km} / \mathrm{h}$ at the reference (solid black line) and test (dotted grey line) section.

Figure 8 shows the time history and frequency content of the vertical free field velocity at the reference and test section during the same train passage. As the train approaches, the measured ground velocity increases, is subsequently followed by a nearly stationary part during the passage, and finally decreases when the train moves away. The passage of individual axles can no longer be distinguished as in the case of the rail response, however. The vibration amplitude decreases with increasing distance from the track; the high frequency components are especially attenuated due to material damping in the soil. Peaks are observed in the frequency spectrum near $10 \mathrm{~Hz}$ and $30 \mathrm{~Hz}$. Figures $8 \mathrm{a}$ and $8 \mathrm{~b}$ indicate that the response at $10 \mathrm{~m}$ and $14 \mathrm{~m}$ from the track is slightly larger at the test section than at the reference section. As can be observed in figures $8 \mathrm{c}$ and $8 \mathrm{~d}$, the vibration levels at $18 \mathrm{~m}$ and $32 \mathrm{~m}$ from the track (i.e. behind the barrier) are significantly lower at the test section than at the reference section, especially from $8 \mathrm{~Hz}$ upwards. This clearly suggests that the jet grouting wall is effectively reducing the vibration levels. 

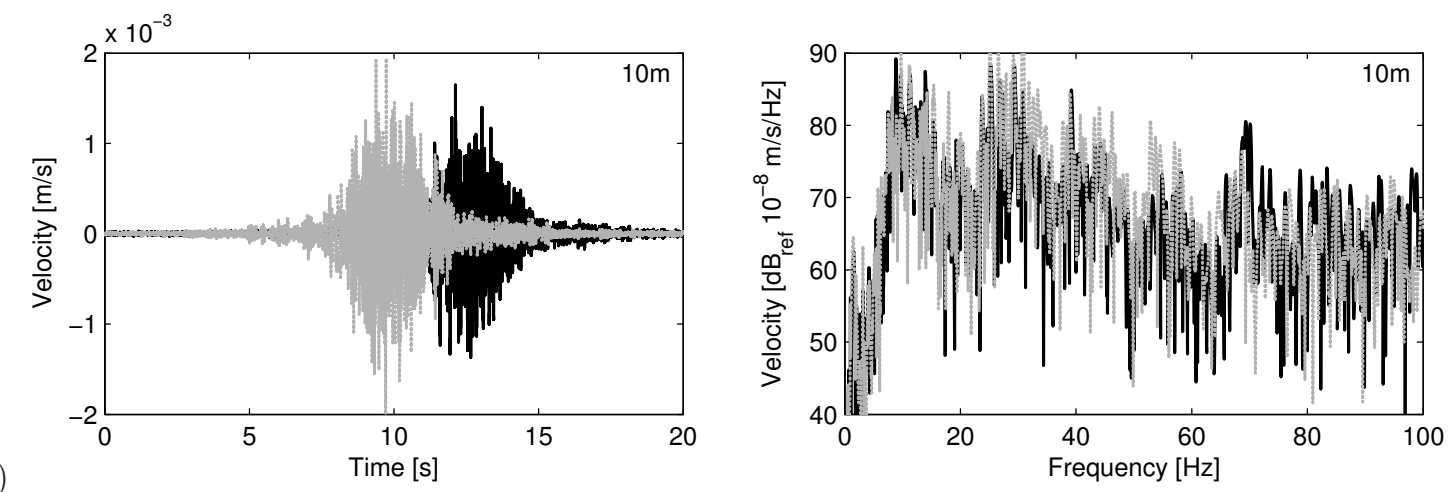

(a)
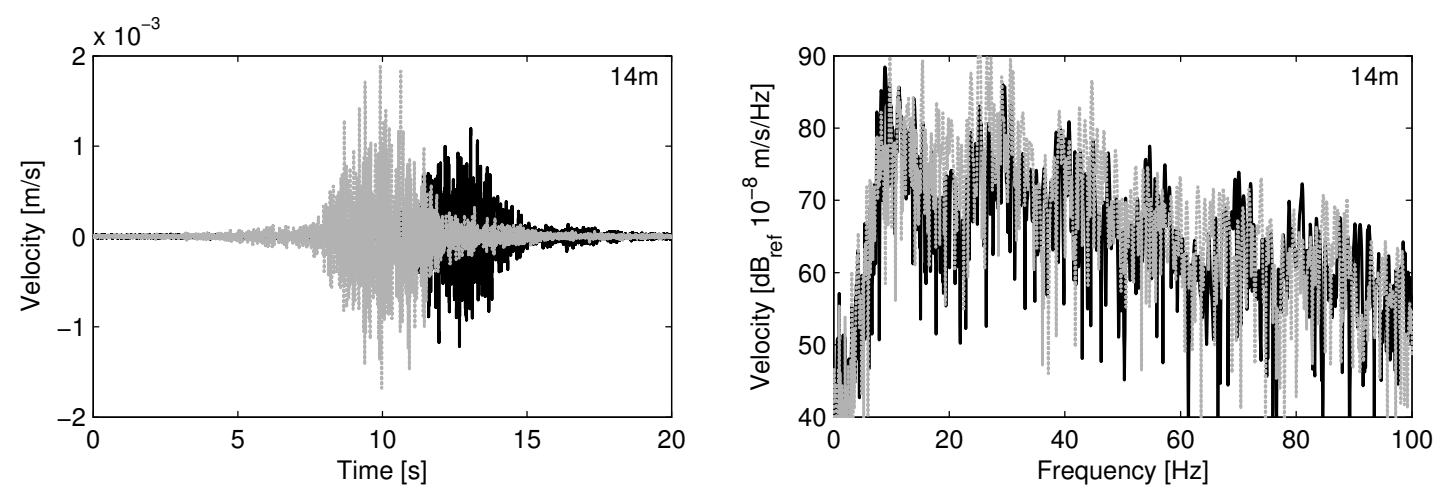

(b)
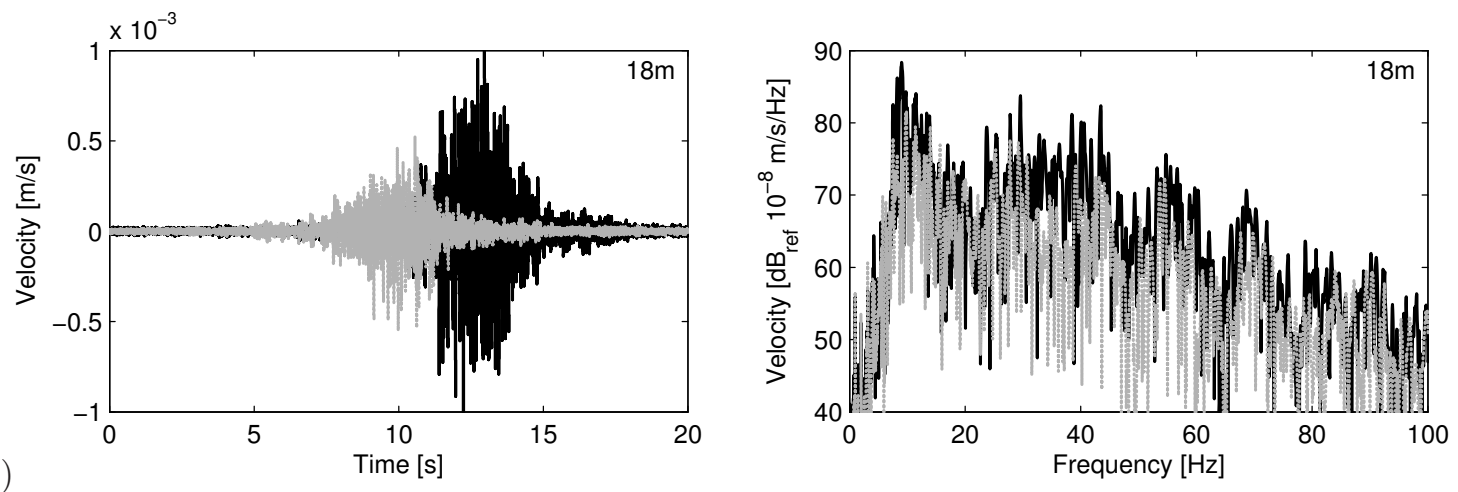

(c)
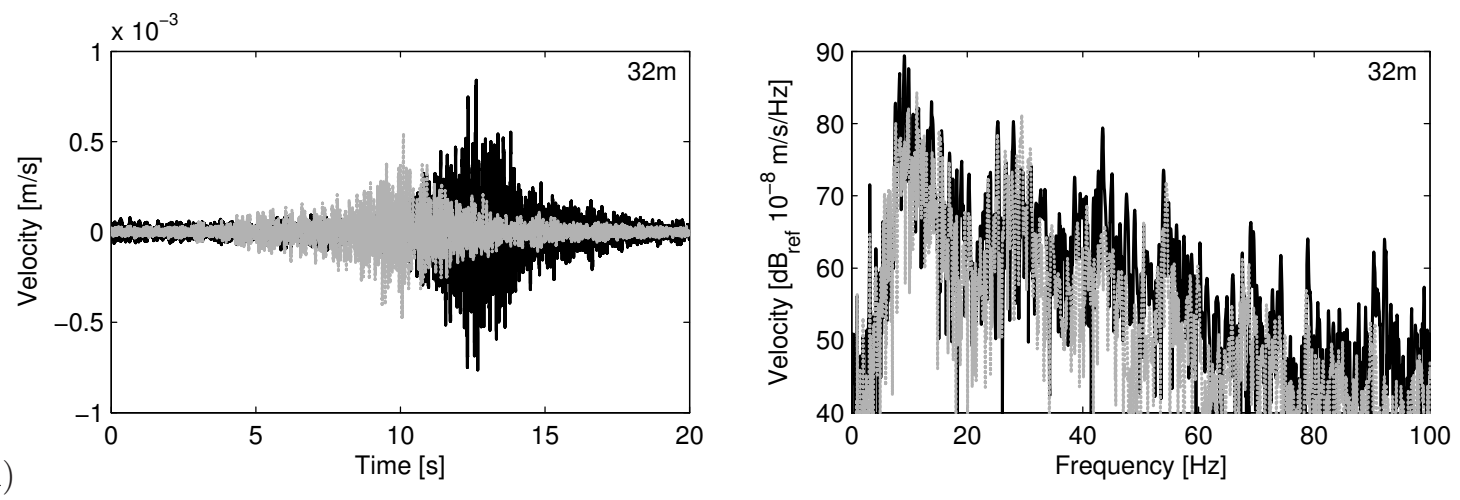

Figure 8: Time history (left) and frequency content (right) of the measured vertical free field vibration during the passage of a S592 commuter train at a speed of $117 \mathrm{~km} / \mathrm{h}$ at the reference (solid black line) and test (dotted grey line) section, at (a) $10 \mathrm{~m}$, (b) $14 \mathrm{~m},(\mathrm{c}) 18 \mathrm{~m}$, and (d) $32 \mathrm{~m}$ from the outer rail. 
Vibrations due to train passages can also be quantified in terms of the vibration velocity level $L_{\mathrm{v}}(f)$, which is defined as the one-third octave band spectrum of the stationary part of the vibration velocity $v_{z \operatorname{RMS}}(f)$ :

$$
L_{\mathrm{v}}(f)=20 \log _{10}\left(\frac{v_{z \mathrm{RMS}}(f)}{v_{0}}\right)
$$

where $v_{z \operatorname{RMS}}(f)$ is the running Root Mean Square (RMS) value of the velocity, while $v_{0}=10^{-8} \mathrm{~m} / \mathrm{s}$ represents a reference velocity. The stationary part of the measured response during a train passage is selected using the German DIN standard [44]. Figure 9 shows the measured vibration velocity levels $L_{\mathrm{v}}(f)$ during the passages of all S592 commuter trains before and after construction of the jet grouting wall at the reference and test section, respectively. The arithmetically averaged vibration velocity levels $\bar{L}_{\mathrm{v}}(f)$ are also superimposed on figure 9. Although train passages of the same train type at approximately the same speed are considered, a considerable variation is observed in the frequency spectrum. This variability is caused by differences in train properties (train speed, wheel unevenness) and the variation of track characteristics (rail unevenness, ballast stiffness) and soil conditions (water table) in space and time. It is crucial to take the latter into account when evaluating the performance of the jet grouting wall. Despite the large variability between different train passages, it is nevertheless clear from figures $9 \mathrm{c}$ and $9 \mathrm{~d}$ that the installation of the barrier leads to a significant reduction of vibration levels at the test section.

The vibration reduction effectiveness of the jet grouting wall is quantified by means of the vertical insertion loss $\mathrm{IL}_{z}(f)$. A first straightforward approach for determining $\mathrm{IL}_{z}(f)$ consists of comparing vibration velocity levels at the test section before and after installation of the barrier:

$$
\mathrm{IL}_{z}(f)=L_{\mathrm{v}}^{\text {test, before }}(f)-L_{\mathrm{v}}^{\text {test,after }}(f)
$$

This approach does not account for the changing train, track, and soil conditions in time, however, which might be significant as there was a two month period between the measurements before and after installation of the barrier. Alternatively, the insertion loss is computed by comparing vibration velocity levels at the reference and test section at the same moment (i.e. after installation of the barrier):

$$
\mathrm{IL}_{z}(f)=L_{\mathrm{v}}^{\text {ref,after }}(f)-L_{\mathrm{v}}^{\text {test, after }}(f)
$$

The track and soil conditions at the reference and test section are not exactly the same, however, hampering the use of equation (3). A more rigorous quantification of the vibration mitigation performance is obtained in a combined procedure, in which measurements at the reference and test section before and after installation of the barrier are simultaneously accounted for [45]:

$$
\begin{aligned}
\mathrm{IL}_{z}(f) & =\left(L_{\mathrm{v}}^{\text {test,before }}(f)-L_{\mathrm{v}}^{\text {test,after }}(f)\right)-\left(L_{\mathrm{v}}^{\text {ref, before }}(f)-L_{\mathrm{v}}^{\text {ref,after }}(f)\right)=\Delta L_{\mathrm{v}}^{\text {test }}(f)-\Delta L_{\mathrm{v}}^{\text {ref }}(f) \\
& =\left(L_{\mathrm{v}}^{\text {ref,after }}(f)-L_{\mathrm{v}}^{\text {test,after }}(f)\right)-\left(L_{\mathrm{v}}^{\text {ref,before }}(f)-L_{\mathrm{v}}^{\text {test,before }}(f)\right)=\Delta L_{\mathrm{v}}^{\text {after }}(f)-\Delta L_{\mathrm{v}}^{\text {before }}(f)
\end{aligned}
$$

The first bracketed term $\Delta L_{\mathrm{v}}^{\text {test }}(f)$ in equation (4) corresponds to equation (2) and characterizes the reduction of vibration levels at the test section, while the second term $\Delta L_{\mathrm{v}}^{\mathrm{ref}}(f)$ is a correction for possible 

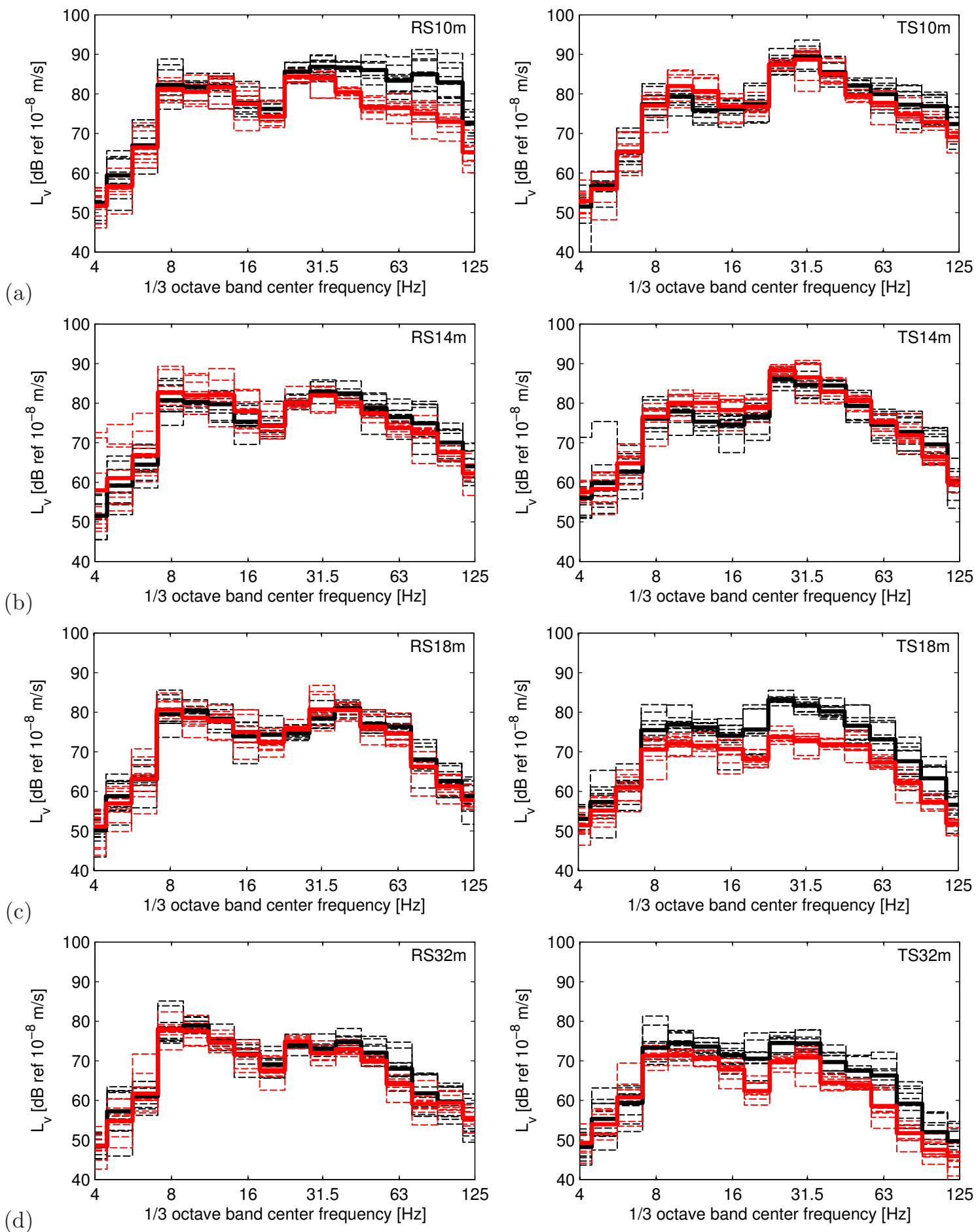

Figure 9: Measured vibration velocity levels $L_{\mathrm{v}}(f)$ in one-third octave bands at the reference (left) and test (right) section during the passage of S592 commuter trains before (dashed black lines) and after (dashed red lines) construction of the jet grouting wall, at (a) $10 \mathrm{~m}$, (b) $14 \mathrm{~m}$, (c) $18 \mathrm{~m}$, and (d) $32 \mathrm{~m}$ from the outer rail. The averaged vibration velocity levels $\bar{L}_{\mathrm{v}}(f)$ are indicated in solid bold lines. 
variations in time, based on measurements at the reference section. The insertion loss is alternatively rewritten as equation (5), where the vibration levels at the reference and test section are compared as in equation (3), with a correction $\Delta L_{\mathrm{v}}^{\text {before }}(f)$ for possible spatial variations between the reference and test section. Both expressions yield the same result, but equation (5) is particularly useful for assessing the variability of the insertion loss $\operatorname{IL}_{z}(f)$. The quantities $\Delta L_{\mathrm{v}}^{\text {after }}(f)$ and $\Delta L_{\mathrm{v}}^{\text {before }}(f)$ can be evaluated for each individual train passage before and after installation of the barrier, respectively, and their sample mean and variance can be computed straightforwardly. This allows estimating the sample variance of the insertion loss $\mathrm{IL}_{z}(f)$ as $\sigma_{\mathrm{IL}_{z}}^{2}(f)=\sigma_{\Delta L_{\mathrm{v}}^{\text {after }}}^{2}(f)+\sigma_{\Delta L_{\mathrm{v}}^{\text {before }}}^{2}(f)$, assuming that $\Delta L_{\mathrm{v}}^{\text {after }}(f)$ and $\Delta L_{\mathrm{v}}^{\text {before }}(f)$ are uncorrelated. This is not the case when employing equation (4), as the quantities $\Delta L_{\mathrm{v}}^{\text {test }}(f)$ and $\Delta L_{\mathrm{v}}^{\text {ref }}(f)$ can only be evaluated using the mean vibration velocity levels $\bar{L}_{\mathrm{v}}(f)$ (as they involve a different set of train passages before and after installation of the barrier).

Figure 10 shows the insertion loss $\mathrm{IL}_{z}(f)$ at $10 \mathrm{~m}, 14 \mathrm{~m}, 18 \mathrm{~m}$, and $32 \mathrm{~m}$ from the track, decomposed according to equations (4) and (5). The interval $\mathrm{IL}_{z}(f) \pm \sigma_{\mathrm{IL}_{z}}(f)$ is superimposed in the second case, clearly illustrating the variability of the experimental results. Especially at low frequencies, a large scatter up to $10 \mathrm{~dB}$ and more is observed. At $18 \mathrm{~m}$ and $32 \mathrm{~m}$, the mean and the confidence interval estimates of the insertion loss are consistently above $0 \mathrm{~dB}$ from $8 \mathrm{~Hz}$ upwards. The mean value reaches a maximum of about $10 \mathrm{~dB}$ near $25-35 \mathrm{~Hz}$ at $18 \mathrm{~m}$, which is also the frequency range where the highest vibration levels are found during train passages. The insertion loss decreases further away from the barrier at $32 \mathrm{~m}$, although it still reaches almost $7 \mathrm{~dB}$ near $20 \mathrm{~Hz}$. These results clearly demonstrate the vibration reduction effectiveness of the jet grouting wall. The mean value of the insertion loss remains close to $0 \mathrm{~dB}$ in front of the barrier, except above $30 \mathrm{~Hz}$ at $10 \mathrm{~m}$, where significant negative values are obtained (indicating an amplification). It is emphasized, however, that this results from a reduction of vibration levels at the reference section (for unclear reasons) and not at the test section, which leads to a negative insertion loss through the correction term $\Delta L_{\mathrm{v}}^{\text {ref }}(f)$ in equation (4). No increase of vibration levels is actually observed at the test section, nor at the reference section (cfr. figure 9a). Figure 10 also illustrates that the correction terms $\Delta L_{\mathrm{v}}^{\text {ref }}(f)$ in equation (4) are significantly smaller than the correction terms $\Delta L_{\mathrm{v}}^{\text {before }}(f)$ in equation (5) (except at $10 \mathrm{~m}$ ), indicating that spatial variations between the reference and test section are more important than variations in time. This suggests that, if no combined procedure can be applied for evaluating the mitigation performance (i.e. if no correction terms can be computed), the methodology corresponding to equation (2) should be favoured over the one corresponding to equation (3).

The experimental results presented in this subsection clearly demonstrate the effectiveness of the stiff wave barrier for reducing the free field response during train passages. Additional experiments have been performed in order to gain further insight in the dynamic behaviour of the barrier, as will be discussed in the following subsections. 

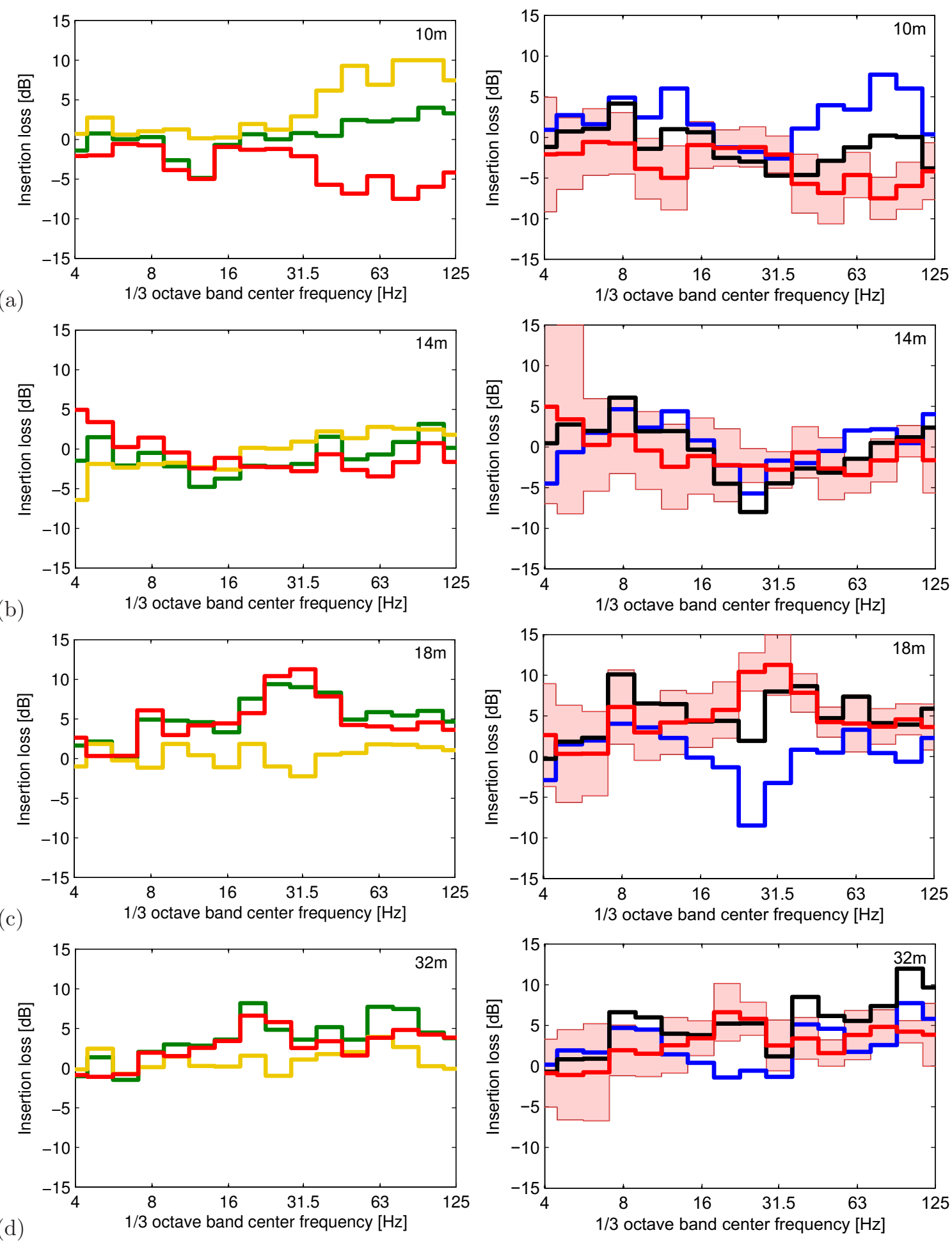

Figure 10: Insertion loss $\mathrm{IL}_{z}(f)$ in one-third octave bands (red line) during the passage of S592 commuter trains at (a) $10 \mathrm{~m}$, (b) $14 \mathrm{~m}$, (c) $18 \mathrm{~m}$, and (d) $32 \mathrm{~m}$ from the outer rail. The insertion loss is decomposed according to equation (4) (left) into $\Delta L_{\mathrm{v}}^{\text {test }}(f)$ (green line) and $\Delta L_{\mathrm{v}}^{\text {ref }}(f)$ (yellow line), and according to equation (5) (right) into $\Delta L_{\mathrm{v}}^{\text {after }}(f)$ (black line) and $\Delta L_{\mathrm{v}}^{\mathrm{before}}(f)$ (blue line). The confidence interval estimates $\mathrm{IL}_{1}(f) \pm \sigma_{\mathrm{IL}_{z}}(f)$ of the measurements are indicated as a shaded area for the second decomposition. 


\subsection{Track receptance tests}

The dynamic axle loads are determined by the vehicle compliance, the track compliance, and the track unevenness $[46,47]$. It is important to investigate whether the track compliance (and thus the generation of dynamic axle loads) is affected by the presence of the jet grouting wall. This is not expected to be the case, as already indicated by figure 7 . Receptance tests have been carried out to validate this assumption.

Hammer impacts were applied at the rail head directly above a sleeper by means of a small and large hammer with a mass of $0.45 \mathrm{~kg}$ and $5 \mathrm{~kg}$, respectively, using both soft and stiff hammer tips. The corresponding response of the rail was measured with two accelerometers installed on the rail head and web. The tests have been performed at the reference and test section, before and after installation of the barrier, under unloaded track conditions. Although loaded conditions are relevant for the actual vehicle-track interaction problem, these tests under unloaded conditions also enable to assess the impact of the jet grouting wall. Approximately 15 hammer impacts have been applied with each hammer at each section in order to improve the signal-to-noise ratio. The average force-acceleration transfer functions have been determined using the $H_{1}$-estimator. Figure 11 shows the force-acceleration transfer function at the rail head as obtained using a small hammer with a stiff tip. A good agreement between the measurements before and after construction of the jet grouting wall up is observed at the reference and test section up to a frequency of $50 \mathrm{~Hz}$, while larger deviations arise at higher frequencies. A possible explanation is that the ballast has been tamped in the period between the track receptance measurements. As similar discrepancies emerge at the test and reference section, it is reasonable to assume that these can be attributed to a variation of ballast characteristics in time rather than to the presence of the jet grouting wall.
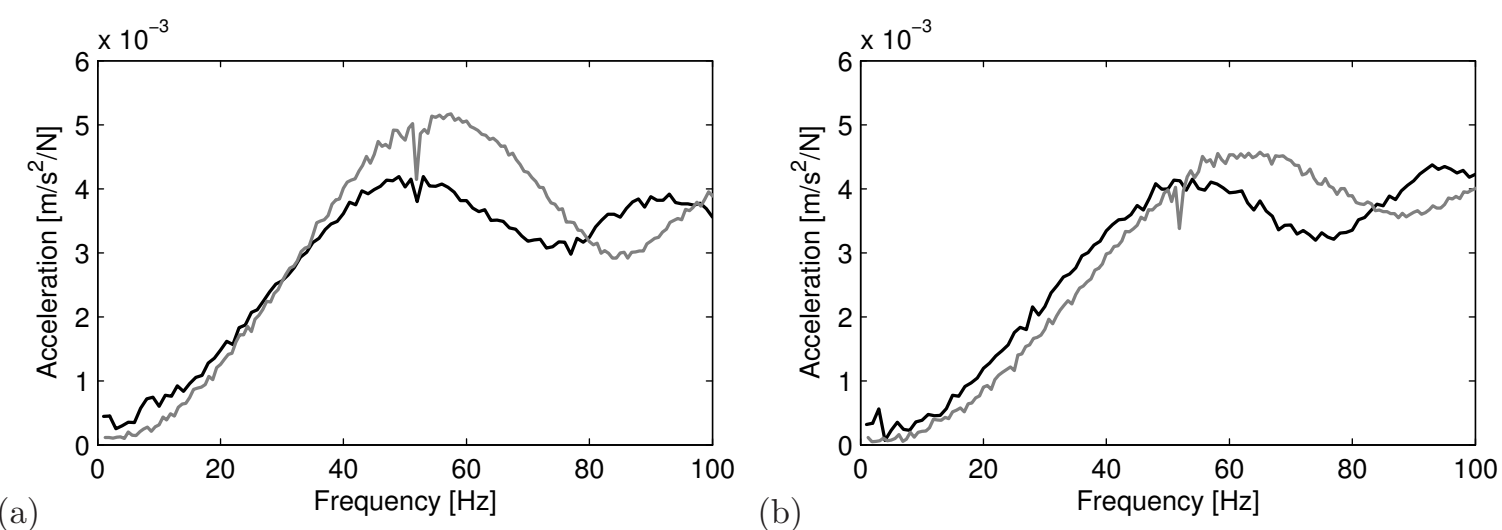

Figure 11: Measured force-acceleration transfer function at the rail head at the (a) reference and (b) test section, before (black line) and after (grey line) construction of the jet grouting wall.

It can be concluded from figures 7 and 11 that the installation of the barrier does not affect the track compliance and, therefore, the dynamic axle loads. The reduction of vibration levels observed during train 
passages is therefore purely caused by impeding the transfer between the track and the free field and not by a reduction of the dynamic axle loads.

\subsection{Transfer functions between the track and the free field}

Transfer functions between the track and the free field have been measured before (August 2012) and after (December 2013) installation of the jet grouting wall. In August 2012, transfer functions have been recorded at both the reference and test section; in December 2013, the measurements were limited to the test section due to time and budget constraints. It is consequently not possible to apply a combined procedure as presented in subsection 3.1 for evaluating the effectiveness of the barrier.

A hammer with a mass of $5 \mathrm{~kg}$ was used to generate vertical impacts on the rail at five locations (at $y=-24 \mathrm{~m}, y=-12 \mathrm{~m}, y=0 \mathrm{~m}, y=12 \mathrm{~m}$, and $y=24 \mathrm{~m}$, where $y=0 \mathrm{~m}$ corresponds to the center of the jet grouting wall), while the resulting vertical ground velocity was measured at 24 positions by means of geophones. The impact locations (denoted as A, B, C, D, and E) and the grid of measurement points are indicated on figure 12. This configuration was chosen to enable identification of the critical angle discussed in subsection 2.3. Approximately 100 hammer impacts were applied at each position on the rail; the transfer functions between the impact force and the free field velocity were subsequently determined using the $H_{1}-$ estimator. A total of $5 \times 24=120$ transfer functions have been measured in this way, but only a limited selection is presented in this paper. The transfer functions are denoted as $h_{z z}\left(\mathbf{x}^{\prime}, \mathbf{x}, f\right)$ in the following, where $\mathbf{x}^{\prime}$ and $\mathbf{x}$ indicate the impact and measurement location, respectively. These narrow band transfer functions $h_{z z}\left(\mathbf{x}^{\prime}, \mathbf{x}, f\right)$ are used for determining point transfer mobilities $\operatorname{TM}_{\mathrm{p}}\left(\mathbf{x}^{\prime}, \mathbf{x}, f\right)$, expressed in each one-third octave band $\left[f_{1}, f_{2}\right]$ as:

$$
\mathrm{TM}_{\mathrm{p}}\left(\mathbf{x}^{\prime}, \mathbf{x}, f\right)=10 \log _{10}\left[\frac{1}{f_{2}-f_{1}} \int_{f_{1}}^{f_{2}}\left|h_{z z}\left(\mathbf{x}^{\prime}, \mathbf{x}, f\right)\right|^{2} \mathrm{~d} f\right]
$$

This quantity is often used in hybrid and empirical prediction models [48, 49]. The point transfer mobilities are finally employed for obtaining the insertion loss $\mathrm{IL}_{z}(f)$ according to:

$$
\mathrm{IL}_{z}(f)=\mathrm{TM}_{\mathrm{p}}^{\text {test, before }}\left(\mathbf{x}^{\prime}, \mathbf{x}, f\right)-\mathrm{TM}_{\mathrm{p}}^{\text {test }, \text { after }}\left(\mathbf{x}^{\prime}, \mathbf{x}, f\right)
$$

Figure 13 shows the insertion loss $\mathrm{IL}_{z}(f)$ in one-third octave bands for transfer functions on a line perpendicular to the track (i.e. for the point transfer mobilities $\mathrm{TM}_{\mathrm{p}}(\mathrm{A}, \mathrm{xxA}, f), \mathrm{TM}_{\mathrm{p}}(\mathrm{B}, \mathrm{xxB}, f), \mathrm{TM}_{\mathrm{p}}(\mathrm{C}, \mathrm{xxC}, f)$, $\mathrm{TM}_{\mathrm{p}}(\mathrm{D}, \mathrm{xxD}, f)$, and $\mathrm{TM}_{\mathrm{p}}(\mathrm{E}, \mathrm{xxE}, f)$, where the label $\mathrm{xx}$ represents the distance from the center of the track and equals $10 \mathrm{~m}, 16 \mathrm{~m}, 24 \mathrm{~m}$, or $32 \mathrm{~m}$ ). The results at $48 \mathrm{~m}$ and $64 \mathrm{~m}$ are not shown due to the low signal-tonoise ratio. At all receiver distances under concern (10 $\mathrm{m}$ to $32 \mathrm{~m}$ ), a similar insertion loss is obtained along each of the five measurement lines (A to E) for frequencies below $20 \mathrm{~Hz}$, while the variability is considerably larger at higher frequencies. This might be due to local soil heterogeneities and the contamination of the signals by noise. A positive insertion loss of more than $5 \mathrm{~dB}$ is observed at all distances from as low as 


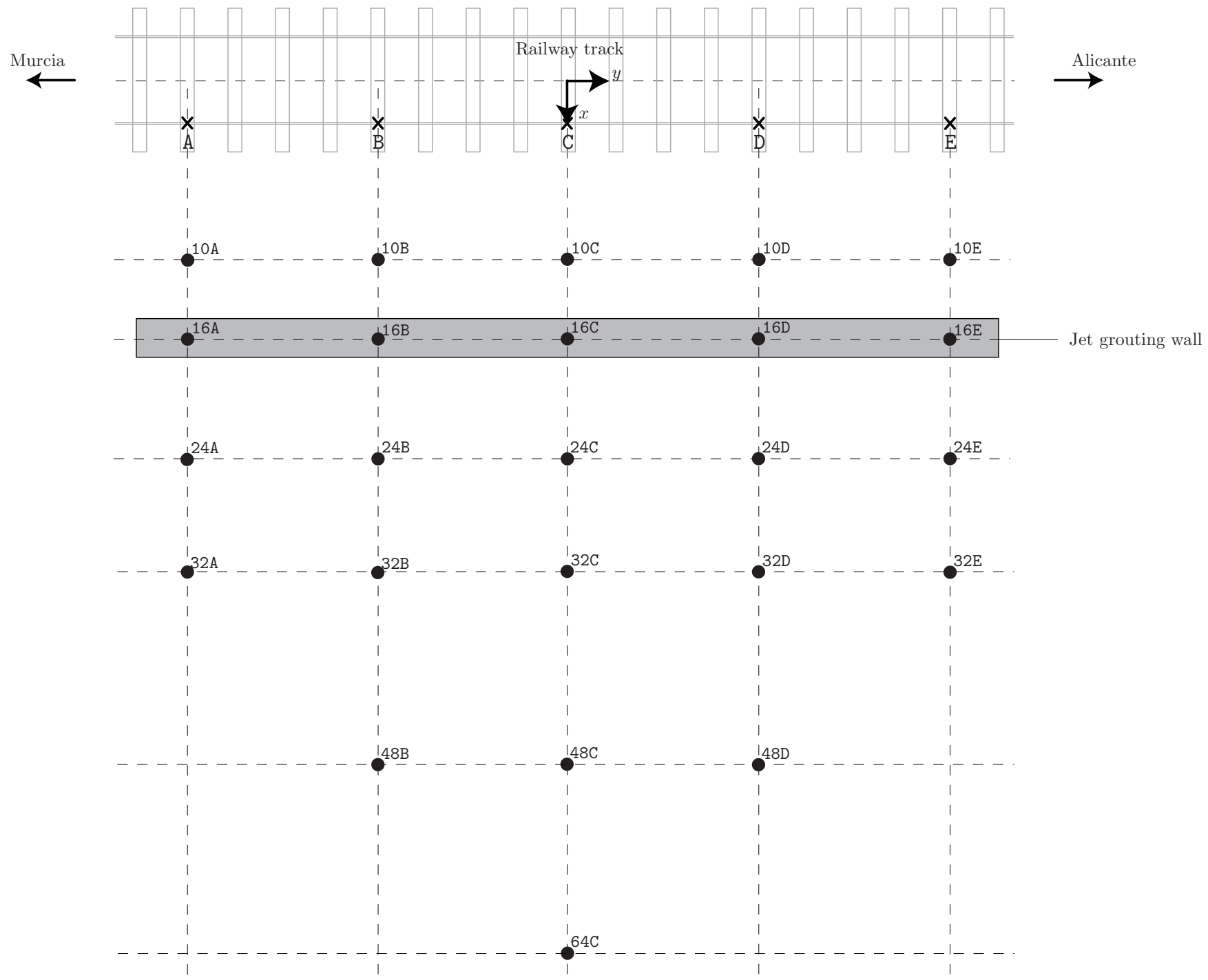

Figure 12: Setup for the measurement of the track - free field transfer functions (figure not to scale).

$4 \mathrm{~Hz}$, but with a strong decrease to negative values near $30 \mathrm{~Hz}$. This result is rather unrealistic and is not in agreement with the observations in subsection 3.1. In particular, the large positive and negative insertion loss values in front of the barrier (at $10 \mathrm{~m}$ ) seem to contradict the observation that the free field response at this location during train passages (figures 9 and 10) is almost unaffected by the presence of the barrier. A possible explanation is the fact that the ballast has been tamped in the period of more than one year between both measurements. This is likely to have affected the track characteristics and thus the transfer from the track to the free field; the resulting insertion loss is hence probably caused by changing track (and possibly soil) characteristics rather than by the presence of the barrier. It is impossible to rigorously assess this assumption, however, due to the lack of control data on the reference section. 

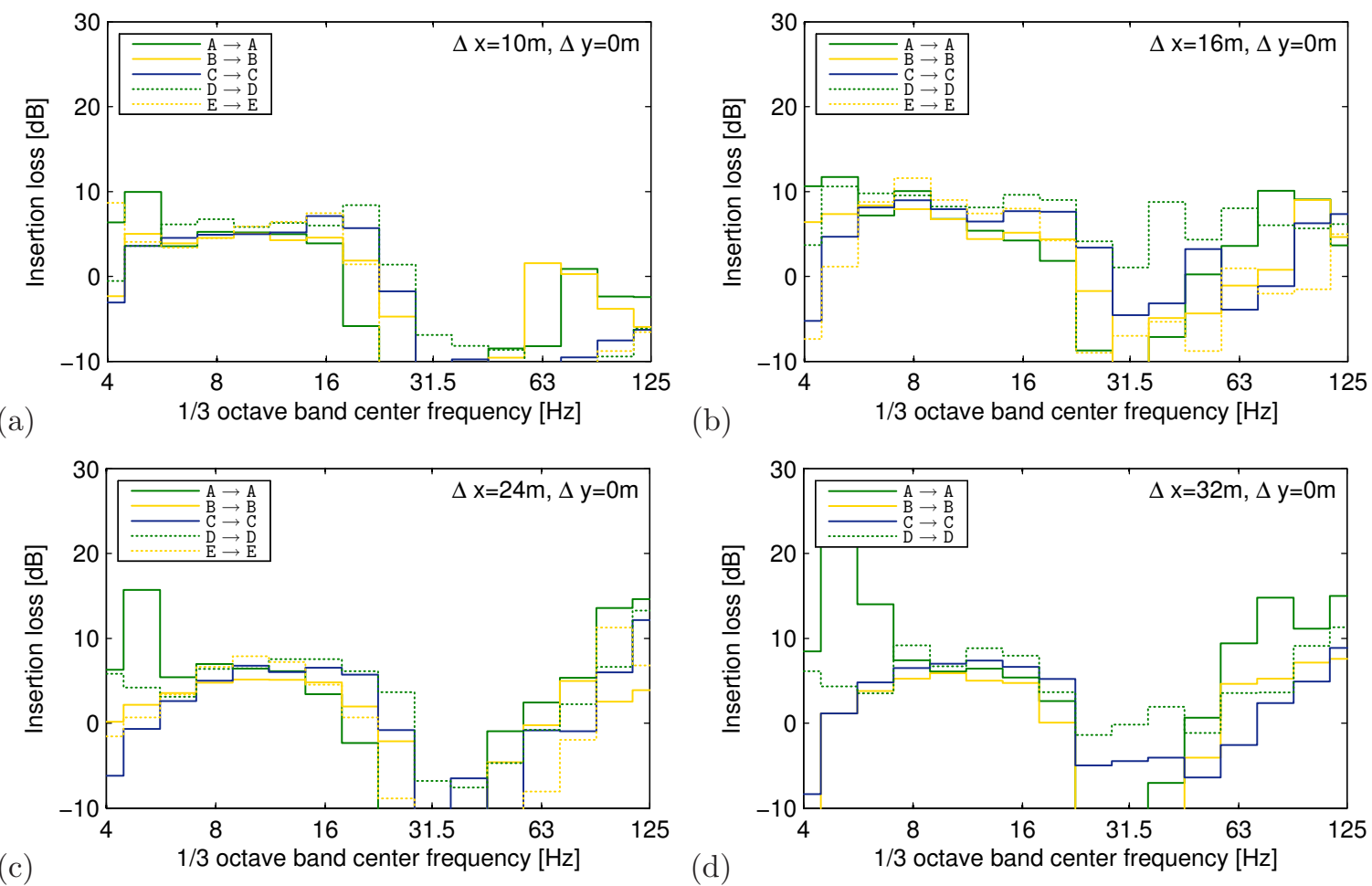

Figure 13: Measured insertion loss $\mathrm{IL}_{z}(f)$ in one-third octave bands for the transfer between the track and the free field on lines perpendicular to the track (i.e. with a longitudinal offset $\Delta y=0 \mathrm{~m}$ ) at a distance of (a) $10 \mathrm{~m}$, (b) $16 \mathrm{~m}$, (c) $24 \mathrm{~m}$, and (d) $32 \mathrm{~m}$ from the center of the track. 
If it is assumed that the observed insertion loss at $10 \mathrm{~m}$ (i.e. in front of the barrier) is purely due to a change of track and soil characteristics in time rather than due the presence of the barrier, the insertion loss at $16 \mathrm{~m}, 24 \mathrm{~m}$, and $32 \mathrm{~m}$ can be corrected by subtracting the insertion loss at $10 \mathrm{~m}$ from the curves shown in figure 13 (assuming that the difference observed in front of the barrier is representative for the other locations). This approximation can be justified by the aforementioned arguments. Figure 14 shows the adjusted insertion loss curves; the arithmetically averaged values are also superimposed. The correction leads to an adjusted insertion loss of exactly $0 \mathrm{~dB}$ at $10 \mathrm{~m}$. The insertion loss at the other locations remains very limited for frequencies up to $30 \mathrm{~Hz}$, while an increase up to $10 \mathrm{~dB}$ and more is observed at higher frequencies. The insertion loss at low frequencies between $8 \mathrm{~Hz}$ and $30 \mathrm{~Hz}$ during train passages, as observed in figure 10, is thus unlikely to be caused by a reduction of the transfer from those axle loads that have a longitudinal offset $\Delta y=0 \mathrm{~m}$ with the point of observation in the free field.
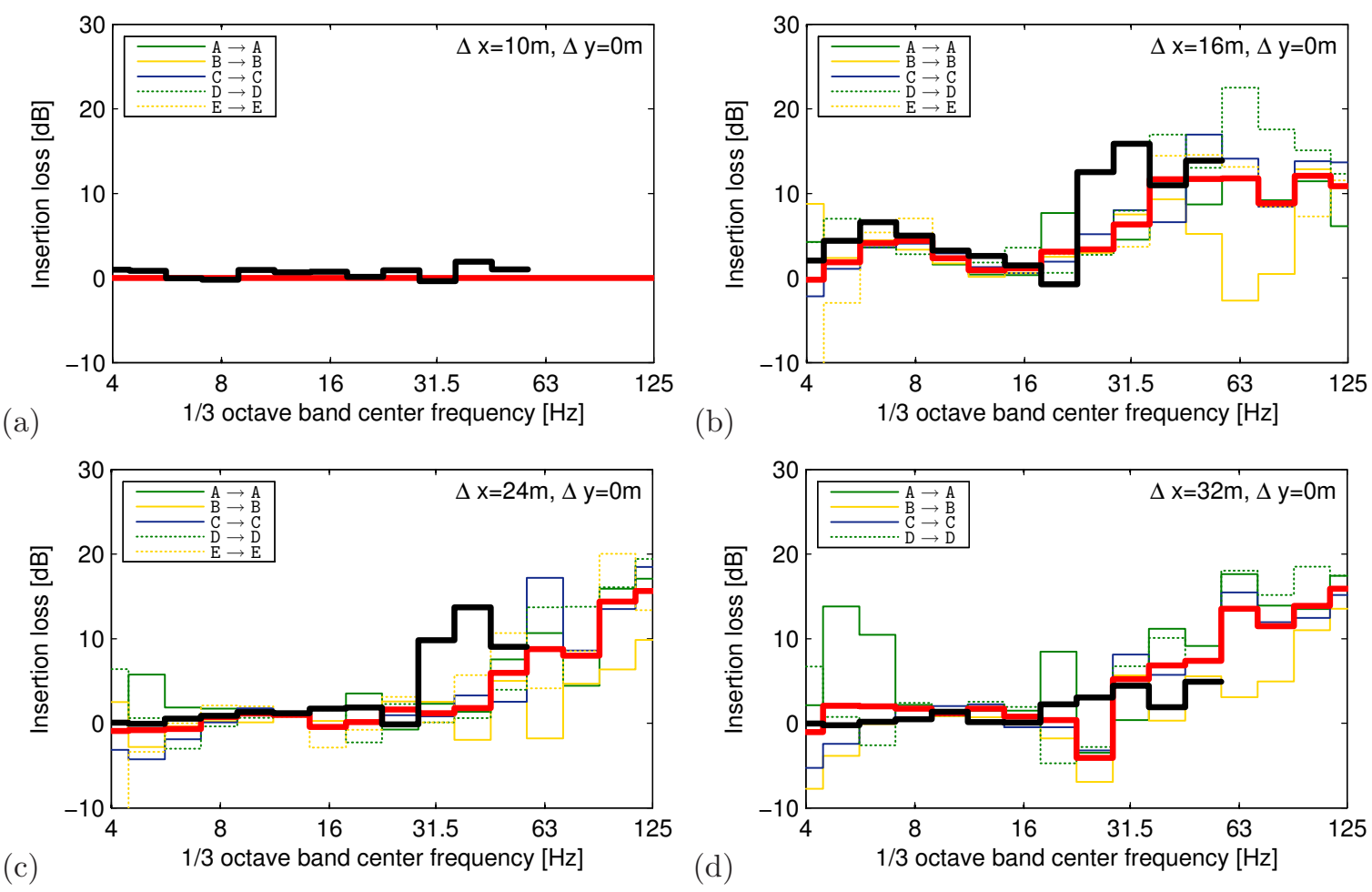

Figure 14: Predicted (black line) and adjusted measured (coloured lines) insertion loss $\mathrm{IL}_{z}(f)$ in one-third octave bands for the transfer between the track and the free field on lines perpendicular to the track (i.e. with a longitudinal offset $\Delta y=0 \mathrm{~m}$ ) at a distance of (a) $10 \mathrm{~m}$, (b) $16 \mathrm{~m}$, (c) $24 \mathrm{~m}$, and (d) $32 \mathrm{~m}$ from the center of the track. The arithmetically averaged insertion loss is indicated in bold.

The measurement grid outlined in figure 12 also allows evaluating the transfer functions for points that are not situated on a line perpendicular to the track. Figure 15 shows the insertion loss for transfer functions between the track and the free field with an offset in the longitudinal direction of $\Delta y=24 \mathrm{~m}$ (i.e. for the 
point transfer mobilities $\mathrm{TM}_{\mathrm{p}}(\mathrm{A}, \mathrm{xxC}, f), \mathrm{TM}_{\mathrm{p}}(\mathrm{B}, \mathrm{xxD}, f), \mathrm{TM}_{\mathrm{p}}(\mathrm{C}, \mathrm{xxA}, f), \mathrm{TM}_{\mathrm{p}}(\mathrm{C}, \mathrm{xxE}, f), \mathrm{TM}_{\mathrm{p}}(\mathrm{D}, \mathrm{xxB}, f)$, and $\left.\mathrm{TM}_{\mathrm{p}}(\mathrm{E}, \mathrm{xxC}, f)\right)$. Once again, a large variability is observed at frequencies above $20 \mathrm{~Hz}$. Furthermore, the insertion loss at $10 \mathrm{~m}$ attains unexpectedly large positive and negative values, which is rather unrealistic. Correcting these results by subtracting the insertion loss at $10 \mathrm{~m}$ leads to adjusted insertion loss curves shown in figure 16. These curves show significant insertion loss values from approximately $8 \mathrm{~Hz}$ upwards, with peaks near $25-35 \mathrm{~Hz}$. The insertion loss is the largest at a distance of $16 \mathrm{~m}$ (i.e. on top of the barrier) and attains at this location a peak value of more than $20 \mathrm{~dB}$, while a decrease is observed further away from the barrier. The insertion loss is in general larger than for the transfer to points on a line perpendicular to the track (figure 14), especially at low frequencies. It can thus be concluded that the reduction obtained at low frequencies for train passages (figure 10) is mainly caused by impeding the transfer from axle loads that have a certain offset in the longitudinal direction with the point of observation in the free field.

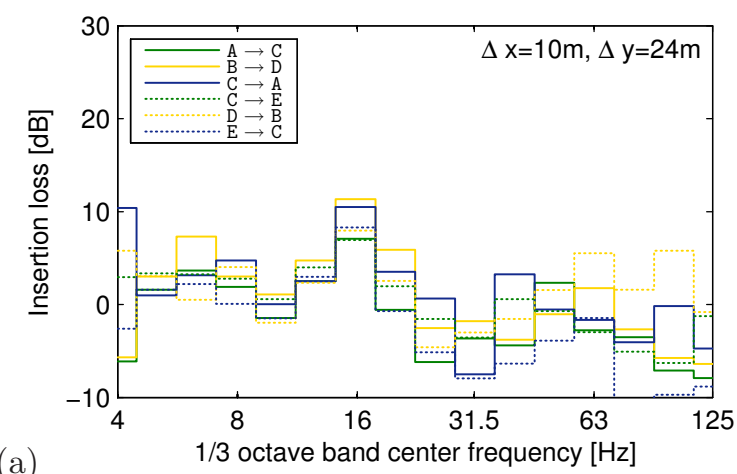

(a)
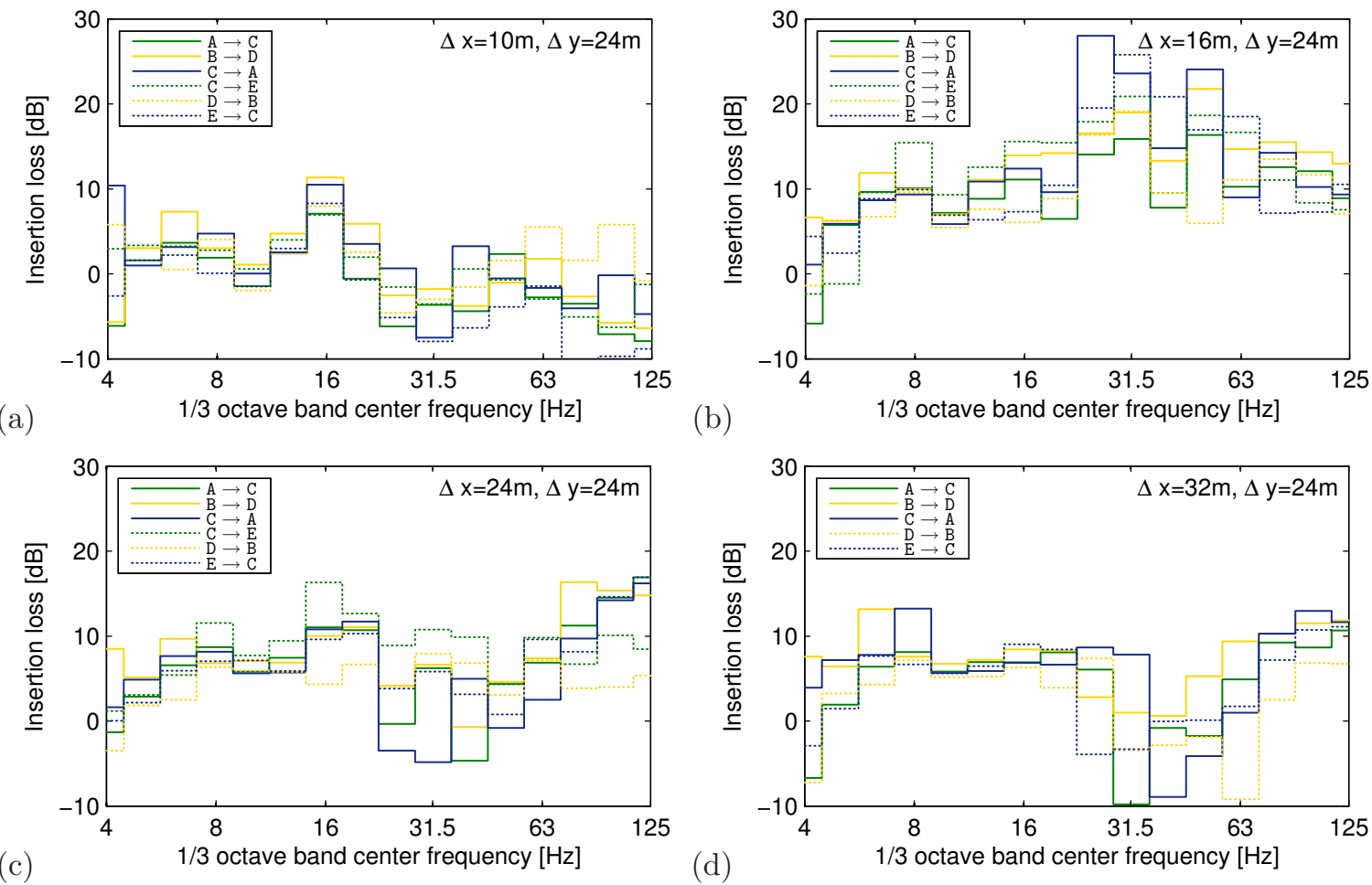

Figure 15: Measured insertion loss $\operatorname{IL}_{z}(f)$ in one-third octave bands for the transfer between the track and the free field with a longitudinal offset $\Delta y=24 \mathrm{~m}$ at a distance of (a) $10 \mathrm{~m}$, (b) $16 \mathrm{~m}$, (c) $24 \mathrm{~m}$, and (d) $32 \mathrm{~m}$ from the center of the track.

\section{Comparison of experimental and numerical results}

The experimental results are compared in this section to numerical simulations which have been obtained by means of a coupled FE-BE method, accounting for dynamic soil-structure interaction. The railway track 

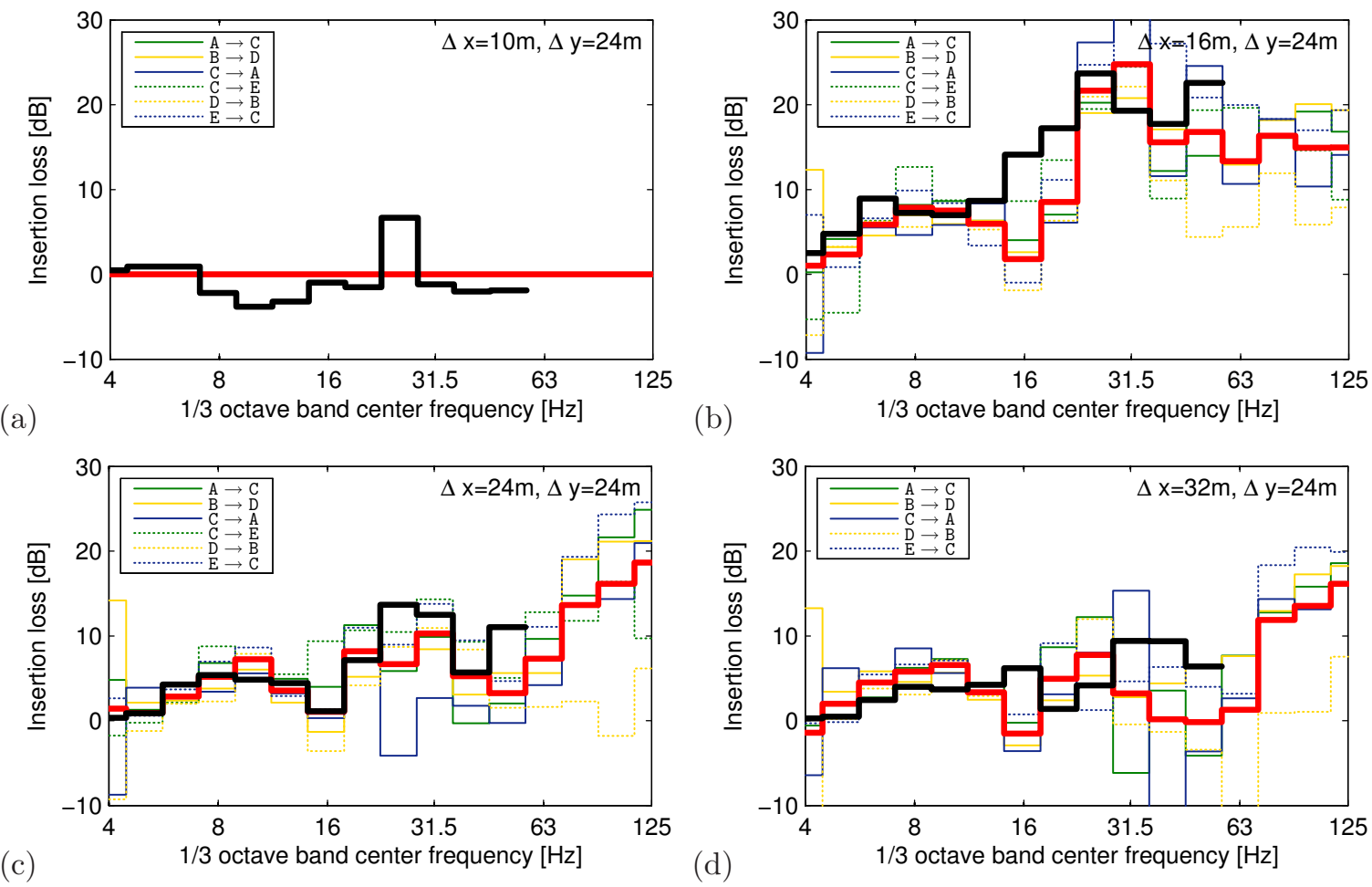

Figure 16: Predicted (black line) and adjusted measured (coloured lines) insertion loss $\operatorname{IL}_{z}(f)$ in one-third octave bands for the transfer between the track and the free field with a longitudinal offset $\Delta y=24 \mathrm{~m}$ at a distance of (a) $10 \mathrm{~m}$, (b) $16 \mathrm{~m}$, (c) $24 \mathrm{~m}$, and (d) $32 \mathrm{~m}$ from the center of the track. The arithmetically averaged insertion loss is indicated in bold. 
and the wave barrier are assumed to be of infinite length, allowing for the application of a computationally efficient 2.5D approach. The longitudinal coordinate $y$ is transformed to the wavenumber $k_{y}$ by means of a forward Fourier transform, and all calculations are performed in the frequency-wavenumber domain. Finite elements are used to model the railway track and the jet grouting wall, which are coupled to a conforming mesh of boundary elements for the soil. The FE and BE discretizations are adjusted to ensure that at least 10 elements per shear wavelength are provided at each frequency. The reader is referred to the literature for a comprehensive overview of this methodology [50].

The numerical prediction of ground vibrations due to a train passage is considered first. This involves the computation of the response due to moving loads, the determination of the dynamic axle loads, and the calculation of the transfer functions from the track to the free field. It has been shown that the dominating stationary part of the free field velocity can be well approximated by a prediction in which the dynamic axle loads are applied at fixed positions [49]; this approach is adopted in this paper. The dynamic axle loads depend on the unevenness experienced by the wheels at the wheel-rail interface. No information is available about the unevenness at the site in El Realengo, however; it is consequently impossible to provide a comparison of measurements and predictions in absolute terms of the vibration velocity levels $L_{\mathrm{v}}(f)$. Therefore, a comparison of the insertion loss $\mathrm{IL}_{z}(f)$ is presented in the following. Figure 17 shows the predicted insertion loss for the passage of a $\mathrm{S} 592$ commuter train at a speed of $117 \mathrm{~km} / \mathrm{h}$. The predictions only extend to $72 \mathrm{~Hz}$ due to stringent memory requirements in the BE formulation. These predictions are compared to the measured insertion loss and the corresponding confidence interval estimate $\operatorname{IL}_{z}(f) \pm \sigma_{\mathrm{IL}_{z}}(f)$. A reasonable qualitative agreement between the predictions and measurements is observed, as the same trends are revealed. Almost no amplification is predicted in front of the barrier (the insertion loss is close to $0 \mathrm{~dB}$ ), which is in agreement with the measurements (except at $10 \mathrm{~m}$ above $30 \mathrm{~Hz}$ ). The predicted insertion loss at $18 \mathrm{~m}$ lays within the estimated confidence interval at low frequencies, but the observed peak of $12 \mathrm{~dB}$ near $30 \mathrm{~Hz}$ is considerably underestimated. This might be caused by the fact that the soil surrounding the barrier has been modified during the installation of the jet grout columns. The predicted insertion loss decreases at larger distances from the barrier, as is also observed in the measurements.

Next, the predicted and measured insertion loss for the transfer functions is compared. Superimposed on figures 14 and 16 are the predicted insertion loss values, as obtained with the 2.5D FE-BE approach. The agreement is reasonable, keeping in mind the variability of the experimental results. The predicted insertion loss is close to $0 \mathrm{~dB}$ at $10 \mathrm{~m}$, which suggests that the procedure adopted for obtaining adjusted experimental insertion loss curves is appropriate. It is important to note that both the measurements and predictions indicate a considerably smaller insertion loss for transfer functions on a line perpendicular to the track (figure 14) than for the other transfer functions (figure 16), especially at low frequencies. This is related to the critical angle that delimits the area where vibration levels are effectively reduced [33], as described in subsection 2.3. The reduction of vibration levels at low frequencies observed during train passages (figure 17) 

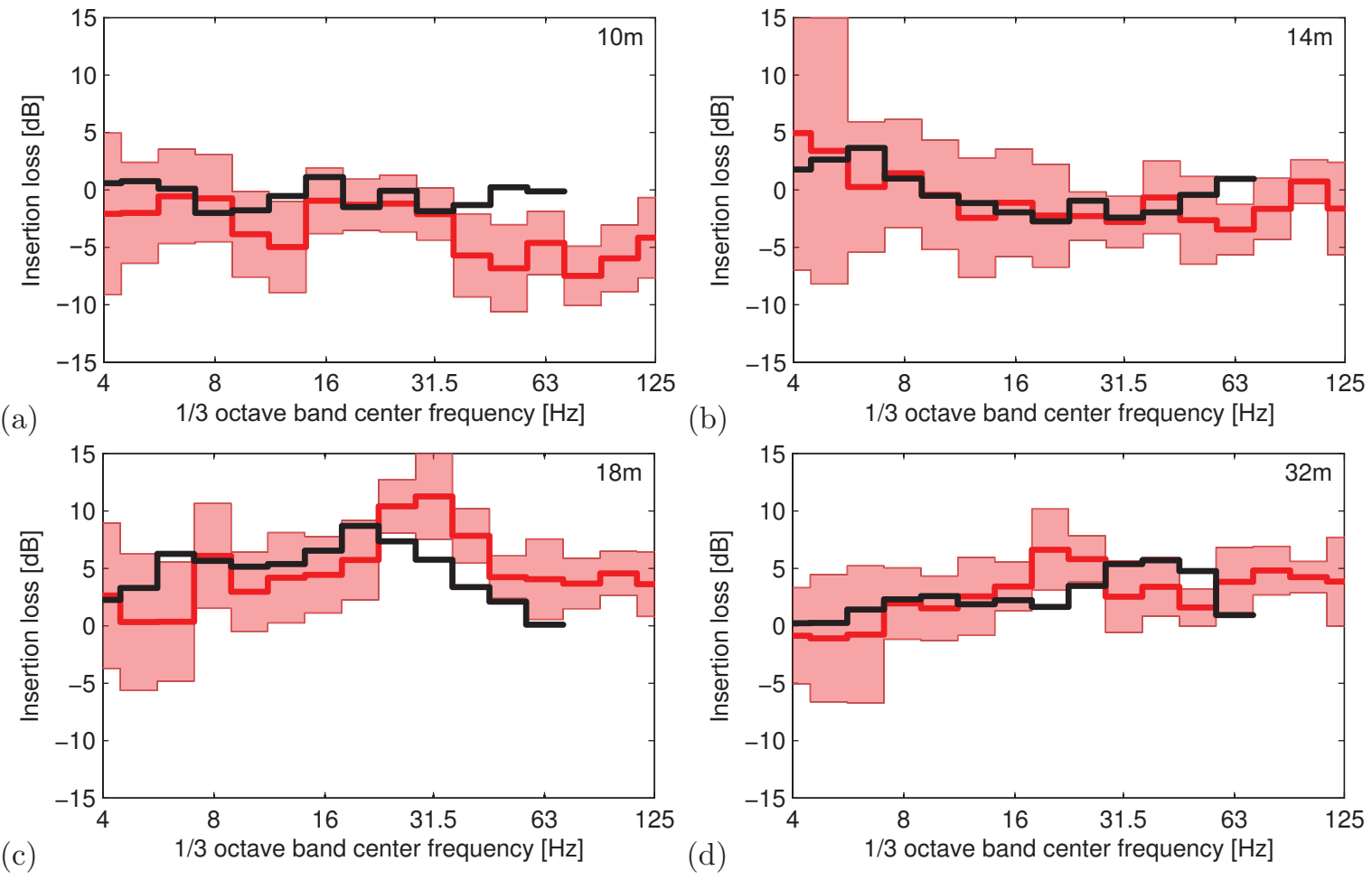

Figure 17: Predicted (black line) and measured (red line) insertion loss $\mathrm{IL}_{z}(f)$ in one-third octave bands during the passage of S592 commuter trains at (a) $10 \mathrm{~m}$, (b) $14 \mathrm{~m}$, (c) $18 \mathrm{~m}$, and (d) $32 \mathrm{~m}$ from the outer rail. The confidence interval estimates $\mathrm{IL}_{z}(f) \pm \sigma_{\mathrm{IL}_{z}}(f)$ of the measurements are indicated as a shaded area. 
is thus mainly caused by impeding the transfer of waves travelling at an oblique angle from the track. The reasonable agreement between measurements and simulations, both for the train passages and the transfer functions, demonstrates that coupled 2.5D FE-BE models can be employed for the design of stiff wave barriers.

\section{Conclusions}

In this paper, the experimental and numerical evaluation of the vibration reduction effectiveness of a stiff wave barrier has been discussed. A site with soft soil characteristics was selected at El Realengo and a full scale in situ test was performed. A barrier of $7.5 \mathrm{~m} \times 1 \mathrm{~m} \times 55 \mathrm{~m}$ composed of overlapping jet grout columns was designed and installed near a conventional railway line. Free field vertical vibration velocities were recorded during several train passages at a test and reference section, before and after installation of the barrier. A combined procedure has been adopted for assessing the effectiveness of the jet grouting wall, hence accounting for varying train, track, and soil properties in space and time. The measurements demonstrate that the barrier is very effective, as insertion loss values of $5 \mathrm{~dB}$ are obtained from $8 \mathrm{~Hz}$ upwards, with a peak of almost $12 \mathrm{~dB}$ near $30 \mathrm{~Hz}$, corresponding to the dominant frequency during train passages. The performance decreases further away from the barrier, although it remains significant (but vibration levels also decrease further away from the barrier). The track receptance and the transfer functions from the track to the free field have furthermore been measured in order to complement the train passage measurements. The performed tests demonstrate that the presence of the barrier only affects the transfer from the track to the free field and not the generation of the dynamic axle loads. A detailed assessment of the transfer functions also indicates that the largest reduction is obtained for waves travelling at an oblique angle from the track. The experimental results for train passages and transfer functions have furthermore been compared to numerical simulations, and a reasonable agreement was found. This in situ test hence serves as a 'proof of concept', demonstrating that stiff wave barriers are capable of significantly reducing vibration levels, provided that they are properly designed.

\section{Acknowledgements}

The results presented in this paper have been obtained within the frame of the EU FP7 project RIVAS (Railway Induced Vibration Abatement Solutions) [34] under grant agreement No. 265754. The authors would like to thank the project partners involved in the realization of the in situ test at El Realengo (Keller

Cimentaciones, ADIF, CEDEX, and UIC), especially Goran Vukotic (Keller Cimentaciones), Álvaro Andrés (ADIF), Miguel Rodríguez (ADIF), all the members of the geophysical and soil dynamic testing groups of CEDEX's Geotechnical Laboratory, and the RIVAS project coordinators Bernd Asmussen and Wolfgang 
Behr (UIC/DB). The first author is a post-doctoral fellow of the Research Foundation Flanders (FWO). The financial support is gratefully acknowledged.

\section{References}

[1] C. Jones, Use of numerical models to determine the effectiveness of anti-vibration systems for railways, Proceedings of the Institution of Civil Engineers-Transport 105 (1) (1994) 43-51.

[2] Y. Yang, H. Hung, A parametric study of wave barriers for reduction of train-induced vibrations, International Journal for Numerical Methods in Engineering 40 (20) (1997) 3729-3747.

[3] A. Kaynia, C. Madshus, P. Zackrisson, Ground vibration from high speed trains: prediction and countermeasure, Journal of Geotechnical and Geoenvironmental Engineering, Proceedings of the ASCE 126 (6) (2000) 531-537.

[4] G. Lombaert, G. Degrande, B. Vanhauwere, B. Vandeborght, S. François, The control of ground borne vibrations from railway traffic by means of continuous floating slabs, Journal of Sound and Vibration 297 (3-5) (2006) $946-961$.

[5] H. Loy, Mitigating vibration using under-sleeper pads, Railway Gazette International 168 (4) (2012) 40-43.

[6] P. Costa, R. Calçada, A. Cardoso, Ballast mats for the reduction of railway traffic vibrations. Numerical study, Soil Dynamics and Earthquake Engineering 42 (2012) 137-150.

[7] H. Hung, Y. Yang, D. Chang, Wave barriers for reduction of train-induced vibrations in soils, Journal of Geotechnical Engineering, Proceedings of the ASCE 130 (12) (2004) 1283-1291.

[8] A. Karlström, A. Boström, Efficiency of trenches along railways for trains moving at sub- or supersonic speeds, Soil Dynamics and Earthquake Engineering 27 (2007) 625-641.

[9] S. François, M. Schevenels, B. Thyssen, J. Borgions, G. Degrande, Design and efficiency of a vibration isolating screen in the soil, Soil Dynamics and Earthquake Engineering 39 (2012) 113-127.

[10] D. Newland, H. Hunt, Isolation of buildings from ground vibration: a review of recent progress, Proceedings of the Institution of Mechanical Engineers, Part C: Journal of Mechanical Engineering Science 205 (1991) 39-52.

[11] J. Talbot, H. Hunt, A generic model for evaluating the performance of base-isolated buildings, Journal of Low Frequency Noise, Vibration and Active Control 22 (3) (2003) 149-160.

[12] R. Woods, Screening of surface waves in soils, Journal of the Soil Mechanics and Foundation Division, Proceedings of the ASCE 94 (SM4) (1968) 951-979.

[13] G. Segol, P. Lee, J. Abel, Amplitude reduction of surface waves by trenches, Journal of the Engineering Mechanics Division, Proceedings of the ASCE 104 (3) (1978) 621-641.

[14] D. Beskos, B. Dasgupta, I. Vardoulakis, Vibration isolation using open or filled trenches. Part I: 2-D homogeneous soil, Computational Mechanics 1 (1986) 43-63.

[15] R. Klein, H. Antes, D. Le Houédec, Efficient 3D modelling of vibration isolation by open trenches, Computers and Structures 64 (1997) 809-817.

[16] D. Connolly, A. Giannopoulos, W. Fan, P. Woodward, M. Forde, Optimising low acoustic impedance back-fill material wave barrier dimensions to shield structures from ground borne high speed rail vibrations, Construction and Building Materials 44 (2013) 557-564.

[17] M. Kim, P. Lee, D. Kim, H. Kwon, Vibration isolation using flexible rubber chip barriers, in: G. Schmid, N. Chouw (Eds.), Proceedings of the International Workshop Wave 2000, Wave propagation, Moving load, Vibration reduction, A.A Balkema, Amsterdam, 2000, pp. 289-298.

[18] A. Alzawi, M. El Naggar, Full scale experimental study on vibration scattering using open and in-filled (geofoam) wave barriers, Soil Dynamics and Earthquake Engineering 31 (3) (2011) 306-317. 
[19] P. Banerjee, S. Ahmad, K. Chen, Advanced application of BEM to wave barriers in multi-layered three-dimensional soil media, Earthquake Engineering and Structural Dynamics 16 (1988) 1041-1060.

[20] L. Andersen, S. Nielsen, Reduction of ground vibration by means of barriers or soil improvement along a railway track, Soil Dynamics and Earthquake Engineering 25 (2005) 701-716.

[21] X. Sheng, C. Jones, D. Thompson, Modelling ground vibrations from railways using wavenumber finite- and boundaryelement methods, Proceedings of the Royal Society A - Mathematical, Physical and Engineering Sciences 461 (2005) 2043-2070.

[22] S. Kattis, D. Polyzos, D. Beskos, Vibration isolation by a row of piles using a 3-D frequency domain BEM, International Journal for Numerical Methods in Engineering 46 (1999) 713-728.

[23] S. Kattis, D. Polyzos, D. Beskos, Modelling of pile wave barriers by effective trenches and their screening effectiveness, Soil Dynamics and Earthquake Engineering 18 (1) (1999) 1-10.

[24] V. Krylov, Scattering of Rayleigh waves by heavy masses as method of protection against traffic-induced ground vibrations, in: H. Takemiya (Ed.), Environmental vibrations. Prediction, Monitoring, Mitigation and Evaluation, Taylor and Francis Group, London, 2005, pp. 393-398.

[25] A. Dijckmans, P. Coulier, J. Jiang, M. Toward, D. Thompson, G. Degrande, G. Lombaert, Mitigation of railway induced vibrations by using heavy masses next to the track, in: A. Cunha, E. Caetano, P. Ribeiro, G. Müller (Eds.), Proceedings of the 9th International Conference On Structural Dynamics, EURODYN 2014, Porto, Portugal, 2014, pp. 751-758.

[26] T. Al-Hussaini, S. Ahmad, J. Baker, Numerical and experimental studies on vibration screening by open and in-filled trench barriers, in: G. Schmid, N. Chouw (Eds.), Proceedings of the International Workshop Wave 2000, Wave propagation, Moving load, Vibration reduction, A.A Balkema, Amsterdam, 2000, pp. 241-250.

[27] E. Celebi, S. Firat, G. Beyhan, I. Cankaya, I. Vural, O. Kirtel, Field experiments on wave propagation and vibration isolation by using wave barriers, Soil Dynamics and Earthquake Engineering 29 (5) (2009) 824-833.

[28] F. De Cock, C. Legrand, Influence of underground gas cushions on the wave propagation of ground vibrations, in: Proceedings of the 4th International Conference on the Application of Stress Wave Theory to Piles, The Hague, The Netherlands, 1992.

[29] K. Massarsch, Vibration isolation using gas-filled cushions, in: Proceedings of the Geo-Frontiers 2005 Congress, American Society of Civil Engineers, Austin, Texas, 2005.

[30] W. Haupt, Model tests on screening of surface waves, in: Proceedings of the 10th International Conference on Soil Mechanics and Foundation Engineering, Vol. 3, 1981, pp. 215-222.

[31] C. Murillo, L. Thorel, B. Caicedo, Ground vibration isolation with geofoam barriers: Centrifuge modeling, Geotextiles and Geomembranes 27 (6) (2009) 423-434.

[32] P. Coulier, H. Hunt, Experimental study of a stiff wave barrier in gelatine, Soil Dynamics and Earthquake Engineering 66 (2014) 459-463.

[33] P. Coulier, S. François, G. Degrande, G. Lombaert, Subgrade stiffening next to the track as a wave impeding barrier for railway induced vibrations, Soil Dynamics and Earthquake Engineering 48 (2013) 119-131.

[34] http://www.rivas-project.eu (2011).

[35] P. Stoffa, P. Buhl, J. Diebold, F. Wenzel, Direct mapping of seismic data to the domain of intercept time and ray parameter - a plane wave decomposition, Geophysics 46 (1981) 255 - 267.

[36] A. Arias, A measure of earthquake intensity, in: R. Hansen (Ed.), Seismic Design in Nuclear Power Plants, MIT Press, Massachusetts, 1970, pp. 438-483.

[37] D. Ewins, Modal testing: theory and practice, Research Studies Press Ltd., Letchworth, UK, 1984.

[38] P. Coulier, A. Dijckmans, S. François, G. Degrande, G. Lombaert, A spatial windowing technique to account for finite dimensions in 2.5D dynamic soil-structure interaction problems, Soil Dynamics and Earthquake Engineering 59 (2014) 
$51-67$.

[39] A. Eringen, E. Suhubi, Elastodynamics, Volume 2, Linear theory, Academic Press, New York, USA, 1975.

[40] P. Coulier, G. Degrande, A. Dijckmans, G. Lombaert, V. Cuéllar, M. Yuste, R. Müller, G. Vucotic, J. Keil, K. Auersch, E. Knothe, W. Rücker, S. Said, J. Jiang, D. Thompson, M. Toward, Design of the mitigation measures at the test sites, RIVAS project SCP0-GA-2010-265754, Deliverable D4.3, Report to the EC (January 2013).

[41] A. Dijckmans, P. Coulier, G. Degrande, G. Lombaert, A. Ekblad, A. Smekal, M. Rodríguez Plaza, A. Andrés-Alguacil, V. Cuéllar, J. Keil, G. Vukotic, Mitigation measures on the transmission path: results of field tests, RIVAS project SCP0-GA-2010-265754, Deliverable D4.5, Report to the EC (December 2013).

[42] G. Lombaert, A. Dijckmans, P. Coulier, G. Degrande, A. Smekal, A. Ekblad, D. Thompson, J. Jiang, M. Toward, W. Rücker, J. Keil, G. Vukotic, M. Rodríguez Plaza, A. Andrés, V. Cuéllar, R. Garburg, R. Müller, Design guide and technology assessment of the transmission mitigation measures, RIVAS project SCP0-GA-2010-265754, Deliverable D4.6, Report to the EC (December 2013).

[43] International Organization for Standardization, ISO 2631-2:1997: Mechanical vibration and shock - Evaluation of human exposure to whole-body vibration - Part 1: General requirements. Second Edition (1997).

[44] Deutsches Institut für Normung, DIN 45672 Teil 2: Schwingungsmessungen in der Umgebung von Schienenverkehrswegen: Auswerteverfahren (1995).

[45] D. Stiebel, Protocol for free field measurements of mitigation effects in the project RIVAS for WP 2, 3, 4, 5, RIVAS project SCP0-GA-2010-265754, Deliverable D1.2, Report to the EC (October 2011).

[46] G. Lombaert, G. Degrande, J. Kogut, S. François, The experimental validation of a numerical model for the prediction of railway induced vibrations, Journal of Sound and Vibration 297 (3-5) (2006) 512-535.

[47] X. Sheng, C. Jones, D. Thompson, A theoretical model for ground vibration from trains generated by vertical track irregularities, Journal of Sound and Vibration 272 (3-5) (2004) 937-965.

[48] C. Hanson, D. Towers, L. Meister, Transit noise and vibration impact assessment, Report FTA-VA-90-1003-06, U.S. Department of Transportation, Federal Transit Administration, Office of Planning and Environment (May 2006).

[49] H. Verbraken, G. Lombaert, G. Degrande, Verification of an empirical prediction method for railway induced vibrations by means of numerical simulations, Journal of Sound and Vibration 330 (8) (2011) 1692-1703.

[50] S. François, M. Schevenels, G. Lombaert, P. Galvín, G. Degrande, A 2.5D coupled FE-BE methodology for the dynamic interaction between longitudinally invariant structures and a layered halfspace, Computer Methods in Applied Mechanics and Engineering 199 (23-24) (2010) 1536-1548. 